University of Nebraska - Lincoln

DigitalCommons@University of Nebraska - Lincoln

$5-12-2005$

\title{
Determination of Dynamic Delamination Toughness of a Graphite- Fiber/Epoxy Composite Using Hopkinson Pressure Bar
}

Xiangfa Wu

Department of Engineering Mechanics, University of Nebraska-Lincoln, xfwu@unlserve.unl.edu

Yuris A. Dzenis

Department of Engineering Mechanics, University of Nebraska-Lincoln, ydzenis@unl.edu

Follow this and additional works at: https://digitalcommons.unl.edu/engineeringmechanicsfacpub

Part of the Mechanical Engineering Commons

Wu, Xiangfa and Dzenis, Yuris A., "Determination of Dynamic Delamination Toughness of a Graphite-Fiber/ Epoxy Composite Using Hopkinson Pressure Bar" (2005). Faculty Publications from the Department of Engineering Mechanics. 21.

https://digitalcommons.unl.edu/engineeringmechanicsfacpub/21

This Article is brought to you for free and open access by the Mechanical \& Materials Engineering, Department of at DigitalCommons@University of Nebraska - Lincoln. It has been accepted for inclusion in Faculty Publications from the Department of Engineering Mechanics by an authorized administrator of DigitalCommons@University of Nebraska - Lincoln. 


\title{
Determination of Dynamic Delamination Toughness of a Graphite-Fiber/Epoxy Composite Using Hopkinson
} Pressure Bar

\author{
Xiang-Fa Wu and Yuris A. Dzenis \\ Department of Engineering Mechanics, Center for Materials Research and Analysis, \\ University of Nebraska-Lincoln, Lincoln, Nebraska 68588-0526 \\ Corresponding author - Xiang-Fa Wu, email xfwu@unlserve.unl.edu
}

\begin{abstract}
Modified dynamic three-point-bending and compact shearing test configurations based on Hopkinson pressure bar (HPB) and crack detection gage (CDG) (Vishay Intertechnology, Inc.) were used for the determination of the dynamic mode I and mode II delamination-initiation toughness of a unidirectional graphite-fiber/epoxy composite made of P7051S-20Q-1000 prepregs (Toray Composites America). The transient loading history was recorded precisely by the HPB installed with a high-resolution digital oscilloscope, and the crack initiation and delay time were captured using the CDG. By means of dynamic finite-element analysis (FEA) of the impact processes with the loading history and crack initiation time as input, the critical dynamic stress intensity factors (DSIFs) $\left(\mathrm{K}_{\mathrm{IDC}} / \mathrm{K}_{\mathrm{I}-}\right.$ IDC) were extracted from numerical results of the crack opening displacements (CODs). Results show that under the present transient loadings, the $\mathrm{K}_{\mathrm{IDC}}$ value is about $80-90 \%$ of the static one, while the $\mathrm{K}_{\mathrm{IIDC}}$ value is nearly unchanged. Dynamic failure mechanisms of the composite specimens were evaluated by fractography using a scanning electron microscope (SEM).
\end{abstract}

\section{Introduction}

Due to their high specific strength and stiffness, excellent fatigue properties, and corrosion resistance, polymer composites made of high modulus fibers in a relatively low modulus polymeric matrix have been finding extensive applications in a wide variety of loading-bearing aerospace, aeronautical, ground vehicles, and sports utilities vehicles. This has resulted in considerably more research on their static, fatigue, and dynamic properties in various service environments in the last three decades [1-10]. Polymer composites are rate-sensitive, and their strength and fracture toughness highly depend upon loading rate and environmental temperature. In the last two decades, numerous investigations have been conducted in understanding the rate effect on delamination toughness of polymer composites [11-23]. To mention a few, under quasi-static loading rate, Daniel and coworkers [11-14] conducted the mode I delamination test of the AS4/3501-6 carbon/epoxy system over a modest range of crosshead displacement rates (from $7.5 \times 10^{-3} \mathrm{~mm} / \mathrm{sec}$ to $460 \mathrm{~mm} / \mathrm{sec}$ ) using a double-cantilever-beam (DCB) specimen configuration. In their investigations, the observed critical mode I strain energy release rate (ERR) $\mathrm{G}_{\mathrm{IC}}$ increases 28\% (from 198 to $254 \mathrm{~J} / \mathrm{m}^{2}$ ) over roughly three orders of magnitude of loading rates, and a power-law empirical formula was suggested. Using a similar method, Smiley and Pipes [15] tested the unidirectional AS4/3501-6 and AS4/PEEK composite samples over roughly five decades of loading rates (from $4.2 \times 10^{-6} \mathrm{~m} /$ $\mathrm{s}$ to $\left.6.7 \times 10^{-1} \mathrm{~m} / \mathrm{s}\right)$. Their results indicated that the critical ERRs of the two material systems have dramatic reductions at high loading rates, and an empirical relation between the mode I fracture toughness and the crack tip opening rate was proposed. Hashemi and Kinloch [18] investigated the effects of specimen geometry, loading rate, and testing temperature on the mode I, mode II, and mixed-mode I/II interlaminar fracture toughness of graphite/epoxy (etherether ketone) composites. They obtained the delamination $R$-curves under various loading cases, which correspond to the fiber bridging and matrix plastic deformation observed near crack tips. By using the double-edge-notched flexural (DENF) specimen configuration, Cantwell [20] and Berger and Cantwell [21] considered the effects of loading rate and temperature on the mode II interlaminar fracture toughness of the AS4/PEEK composites. A fully instrumented drop-weight carriage was introduced for the high loading rate tests. Their test results show that increasing the test temperature leads to a reduction in the mode II interlaminar fracture toughness of the composites, while increasing the crosshead displacement rate has been shown to increase the value of $\mathrm{G}_{\mathrm{IIC}}$ by up to $25 \%$. The rate sensitivity of $\mathrm{G}_{\text {IIC }}$ was attributed to the existence of extensive plastic flow within the crack tip region observed in their sample characterizations. 
Table 1. Mechanical properties of unidirectional composite.*

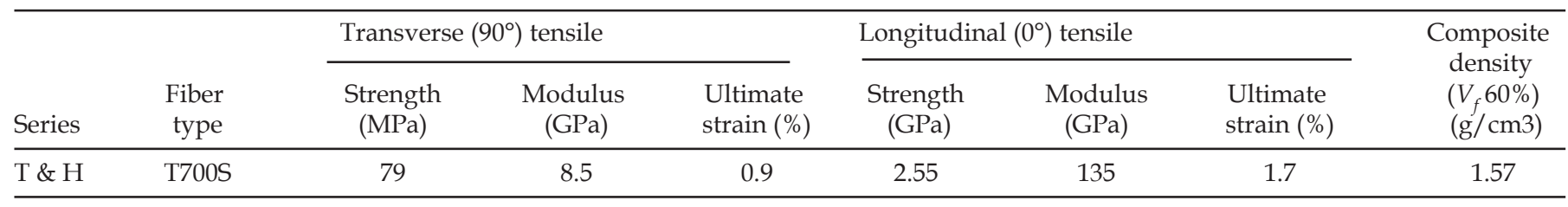

${ }^{*}$ No. 2500-250F curable epoxy.

So far, static and quasi-static fracture behaviors of polymer composites have been extensively investigated, while the dynamic delamination toughness of polymer composites has not yet received as much attention [24]. With the increasing applications of polymer composites, it is necessary to understand their dynamic behaviors under localized impact loadings such as that imparted by a dropped tool or runway debris. In recent years, instrumented impact facilities have been introduced in exploring the impact failure phenomena of polymer composites such as Charpy impact test, Izod impact test, tensile Hopkinsonbar test, gas gun, etc. [2, 25-28]. During an impact fracture test, the most difficult task is how to precisely record the crack growth history. A coherent gradient sensing (CGS) system, in conjunction with high-speed photography, has been developed to capture the real-time interferograms of the near-tip deformation during dynamic crack initiation and growth in specimens [26-28]. In these studies, the impact speeds ranged from $1 \mathrm{~m} / \mathrm{s}$ to $30 \mathrm{~m} / \mathrm{s}$, and the observed crack speed was up to $900-1800 \mathrm{~m} / \mathrm{s}$. The transient critical ERRs were extracted by relating the real-time crack tip displacement field measured by the CGS system. Recently, using the ENF specimen configuration, Tsai et al. [24] introduced an efficient method to capture the mode II and mixed-mode crack growth history by directly depositing an array of conductive aluminum lines created by the vapor deposition technique on the crack growth path. They found that the values of the dynamic mode II fracture toughness of the unidirectional S2/8553 glass/epoxy and AS4/3501-6 carbon/epoxy composites are basically equal to the static ones and not significantly affected by crack speeds up to $1100 \mathrm{~m} / \mathrm{s}$.

Under impact loading, dynamic failure process of solid materials generally consists of damage (micro-crack) nucleation, crack initiation, stable crack growth, and unstable crack propagation. For metallic materials, several wellknown dynamic initiation criteria have been established, i.e., 1) dynamic SIF criterion; 2) dynamic J-integral criterion; 3) least action criterion; 4) minimum time criterion, etc. [29]; however, crack initiation criteria have not been established yet for polymer composites. In this study, we focused our attention on the dynamic crack initiation of a thick unidirectional graphite-fiber/epoxy composite made of 96-layer P7051S-20Q-1000 prepregs supplied by the Toray Composites America. Modified dynamic threepoint-bending and compact shearing test configurations based on Hopkinson pressure bar (HPB) and crack de- tection gage (CDG) (Micromeasurements, Inc.) were used for the determination of the mode I and mode II dynamic delamination-initiation toughness of the unidirectional graphite-fiber/epoxy composite. The transient loading history was recorded precisely using the HPB installed with a high-resolution digital oscilloscope, and the crack initiation and delay time were captured by the CDG. Dynamic finite-element analysis (FEA) was conducted to simulate the impact processes using the recorded loading history and crack initiation time as input. The critical dynamic stress intensity factors (DSIFs) $\left(\mathrm{K}_{\mathrm{IDC}} / \mathrm{K}_{\mathrm{IIDC}}\right)$ were extracted from the FEA results of the crack opening displacements, and detailed fractographic analysis was conducted by using a scanning electron microscope (SEM).

\section{Dynamic Interlaminar Fracture Testing}

\section{Specimen Design and Preparation}

Unlike quasi-static delamination test, impact delamination test needs to be performed on a bulk specimen to minimize the boundary effects. Therefore, a thick unidirectional graphite-fiber/epoxy composite made of 96-layer Toray P7051S-20Q-1000 prepregs was utilized for this purpose. The unidirectional prepregs consisted of T700S graphite fiber in a F250 resin system. Mechanical properties of the unidirectional laminate are tabulated (Table 1).

Laminated panels were assembled following hand layup procedure and cured in a two-chamber press-clave under controlled temperature, pressure, and vacuum environment in accordance with the manufacturer-recommended curing cycle [30]. Artificial delamination (pre-crack) was created by inserting a 12.7- $\mu \mathrm{m}$ thick DuPont Teflon ${ }^{\circledR}$ film between the 48th and 49th plies of the laminated panel during lay-up. Samples were cut from the unidirectional laminated panels using a diamond-coated rotary saw with a water-cooling system, and mounted on steel bases designed for dynamic mode I and mode II delamination tests, as shown in Figures 1 and 2. A Miller Stephenson two-part adhesive was used for sample mounting. Typical sample dimensions were $20 \times 20 \times 12 \mathrm{~mm}$, as shown in Figure 3, and the artificial delamination was about $10 \mathrm{~mm}$ along the fiber direction.

After mounting the sample on its steel bases, one side surface of the sample was polished for identifying the crack tip and mounting the CDG. Artificial pre-crack in each 


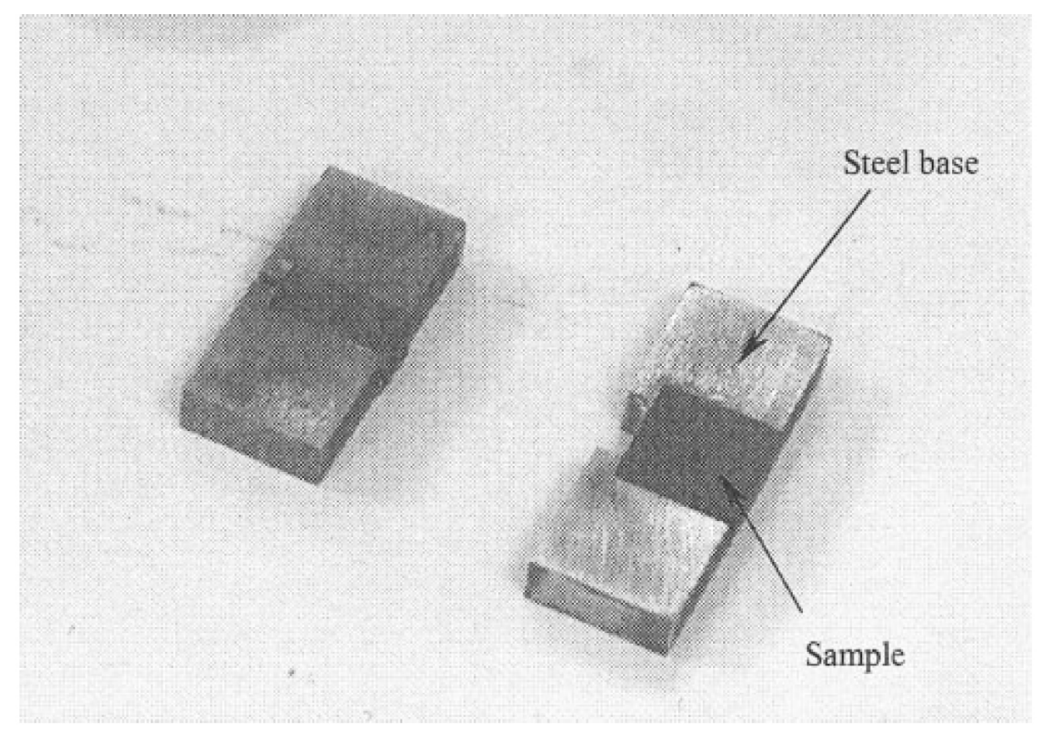

Figure 1. Modified impact three-point bending specimen.

sample was advanced to obtain a natural crack tip using a thin steel wedge with caution. Before mounting the CDG, the polished sample surface was cleaned using alcohol and then neutralized. The advanced crack tip was identified using an optical microscope and marked with a fine pencil. The CDG with a single beryllium alloy wire and polyamide backing was mounted on the marked crack tip using a solvent-thinned adhesive, M-Bond 600/610 (Vishay Intertechnology, Inc.). The CDG wire width was $0.25 \mathrm{~mm}$. After mounting the CDG, the specimen was cured at $80^{\circ} \mathrm{C}$ for $2 \mathrm{hr}$ to maximize the bonding strength. The CDG dimensions are shown in Figure 4, and the CDG circuit is shown in Figure 5.

\section{Experimental Setup for Impact Test}

The impact test was conducted on an experimental setup consisting of a gas gun, a circular high-strength steel striker of length $300 \mathrm{~mm}$, and an HPB of length $1524 \mathrm{~mm}$, as shown in Figure 6. The diameter of both the steel striker and the HPB is $8 \mathrm{~mm}$. The materials of the striker and the $\mathrm{HPB}$ were the same. A modified three-point-bending specimen was used for the dynamic mode I delamination test, while a modified compact shear specimen was utilized for the dynamic mode II delamination test, as illustrated in Figures 6 and 7. Impact force acting on the specimen was induced by the impact of the striker bar on the HPB. The striker was propelled by compressed nitrogen gas in the

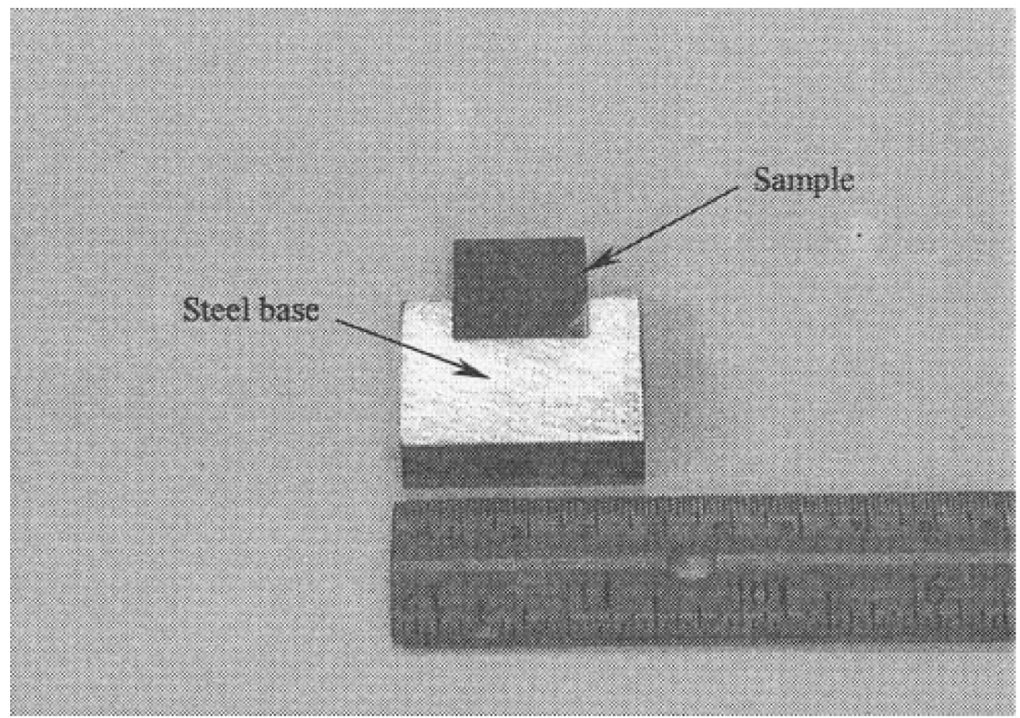

Figure 2. Modified impact shear specimen. 


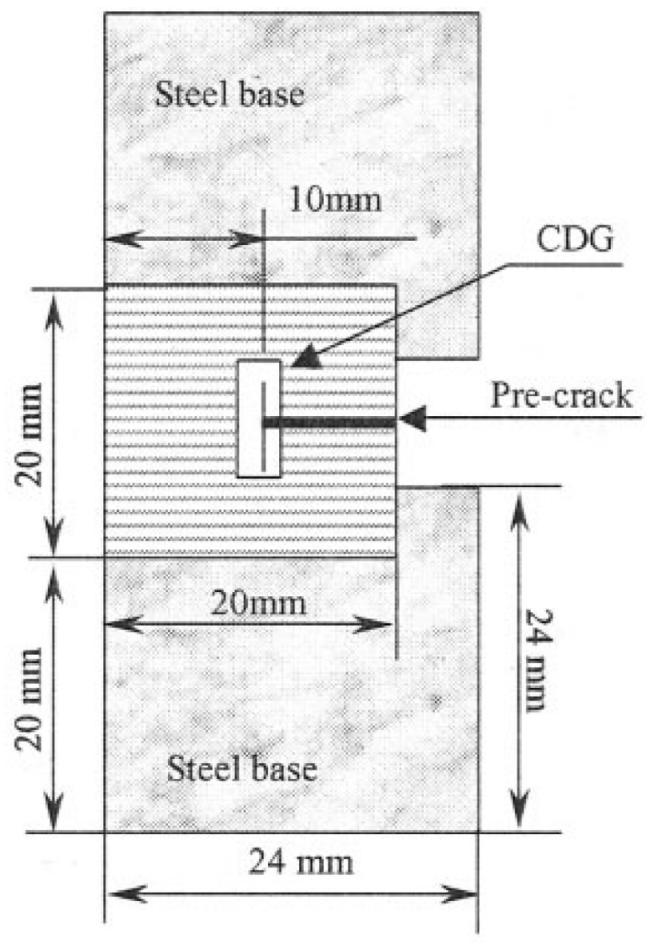

(a) Mode I

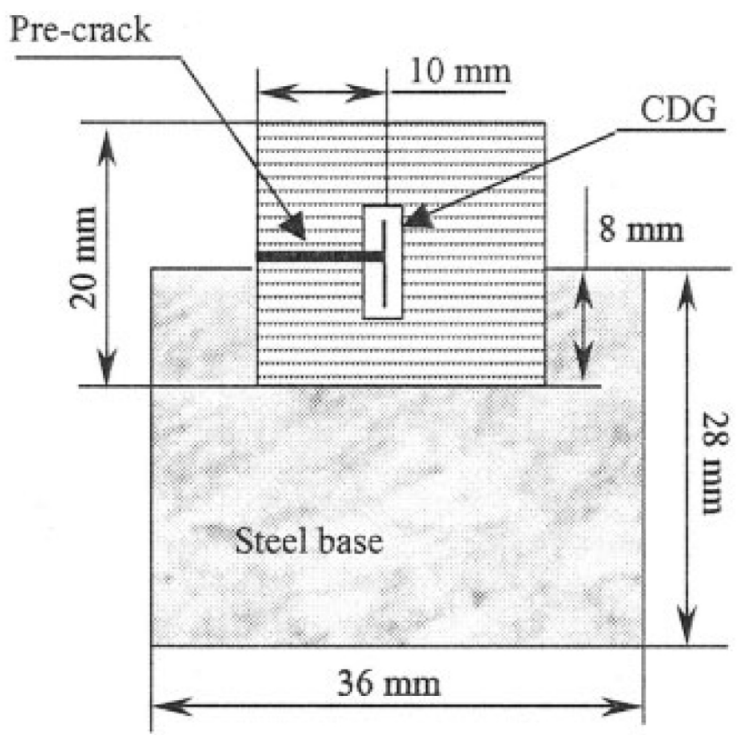

(b) Mode II

Figure 3. Dimensions of impact specimens.

gas gun chamber. Upon impact, a compressive stress was generated in the HPB propagating towards the specimen. The incident pulse on the sample was partially reflected back into the bar and partially transmitted into the sample. The magnitudes and durations of the incident and reflected pulses were recorded using a strain gage sensor installed in the middle of the HPB as shown in Figure 6. The pulse transmitted from the HPB propagated inside the sample and reflected at the sample/steel-base interfaces, pre-crack surfaces, and specimen free surfaces. In the mode I testing case, when the DSIF $\left(\mathrm{K}_{\mathrm{ID}}\right)$ at the pre-crack tip reached the critical value $\mathrm{K}_{\mathrm{IDC}}$, the pre-crack began to grow. As a result, the CDG was broken due to the opening of crack surfaces, and a crack initiation signal was triggered. The stresses in- side the HPB and the crack initiation information were recorded simultaneously using a high-resolution digital oscilloscope. The transient impact force acting on the sample was then precisely determined using the recorded strain gage signals.

In this experimental investigation, nitrogen pressure in the gas gun chamber was chosen around 0.13 $\mathrm{MPa}$ for all the impact tests, and the corresponding striker impact speed was about $20-30 \mathrm{~m} / \mathrm{s}$.

\section{Impact Test Results}

Impact stress acting on sample surface can be calculated from the stress difference of the incident wave and the first

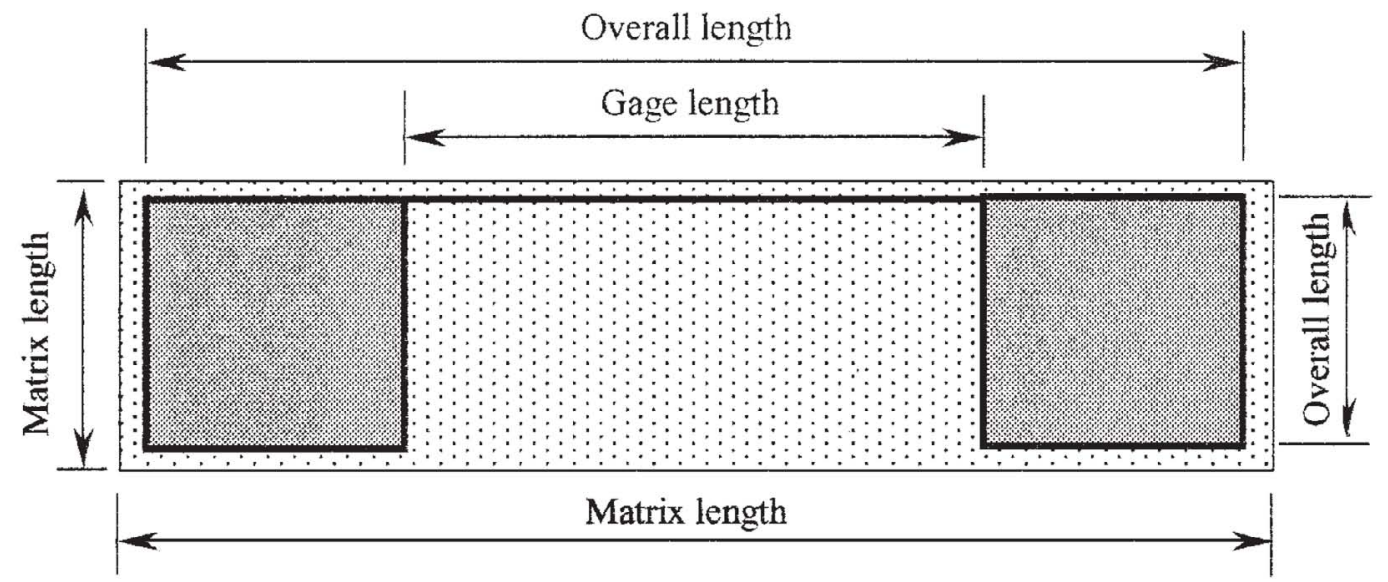

Figure 4. Crack detection gage dimensions. Gage length: $10.2 \mathrm{~mm}$; overall length: $14.2 \mathrm{~mm}$; overall width: $2.5 \mathrm{~mm}$; matrix length: $15.2 \mathrm{~mm}$; matrix width: $3.2 \mathrm{~mm}$. 


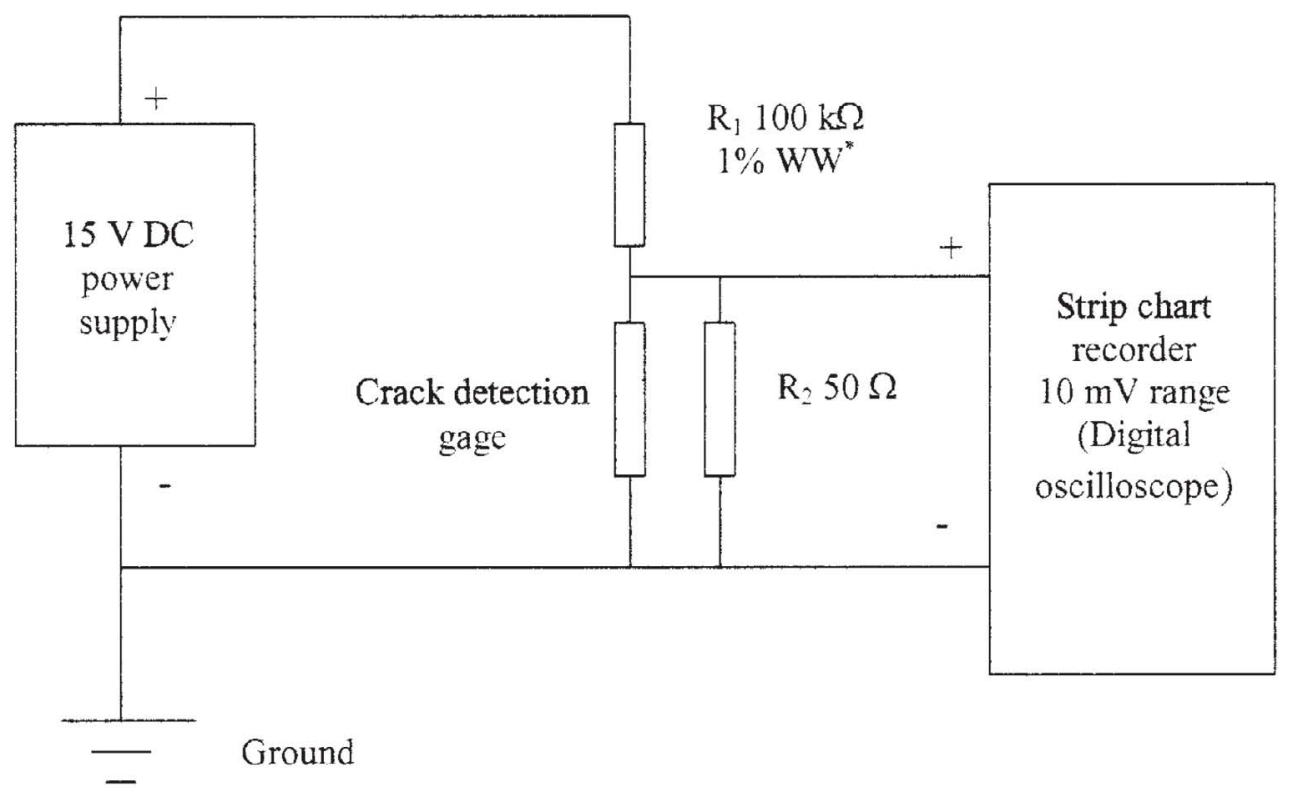

Figure 5. Sampling circuit of crack detection gage.

reflected wave. The transient stress in the HPB was obtained following the Hooke's law, $\sigma=E \varepsilon$, based on the transient strain $\varepsilon$ derived from the circuit relation of the halfbridge Wheaston's circuit such that

$$
\varepsilon=2 \Delta U / S_{g} V
$$

where $\Delta U$ is the voltage measured from the strain gage sensor, $V$ is the excitation voltage, and $S_{g}$ is a strain gage factor, here $S_{g}=2.04$.

Typical stress wave signals recorded from the HPB in the above setups are shown in Figures 8 and 9, respectively. During the impact tests, a soft thin material sheet $(\sim 2 \mathrm{~mm}$ aluminum or copper sheet) was introduced on the incident

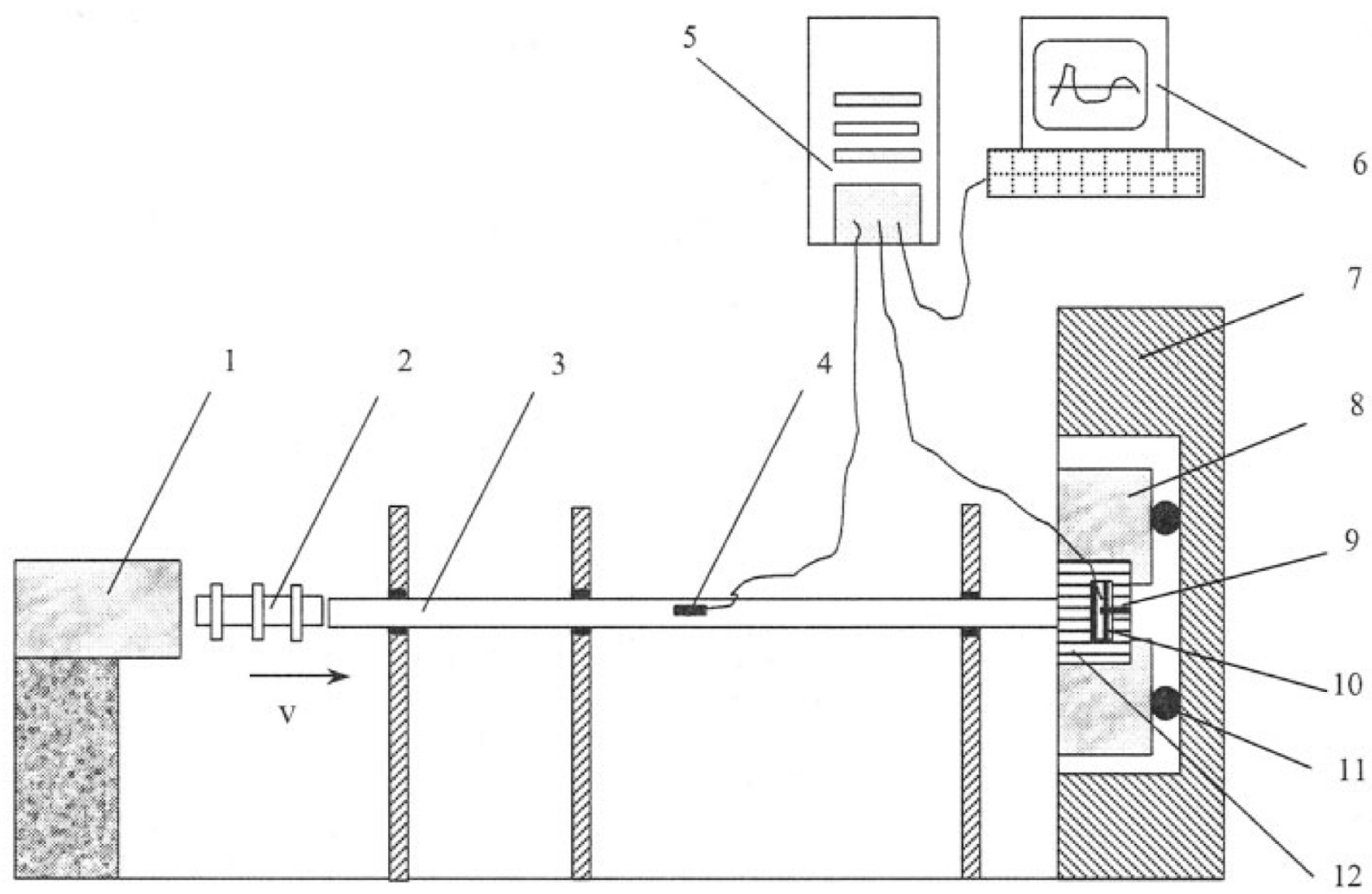

Figure 6. Schematic of HPB setup (mode I case). Note: Specimen and fixture dimensions are greatly exaggerated. 1, gas gun; 2 , striker; 3 , incident bar; 4 , strain gage; 5 , digital oscilloscope; 6 , computer; 7 , fixture base; 8 , sample steel base;

9, artificial crack; 10, crack detection gage (CDG); 11, support pin; 12, composite sample. 


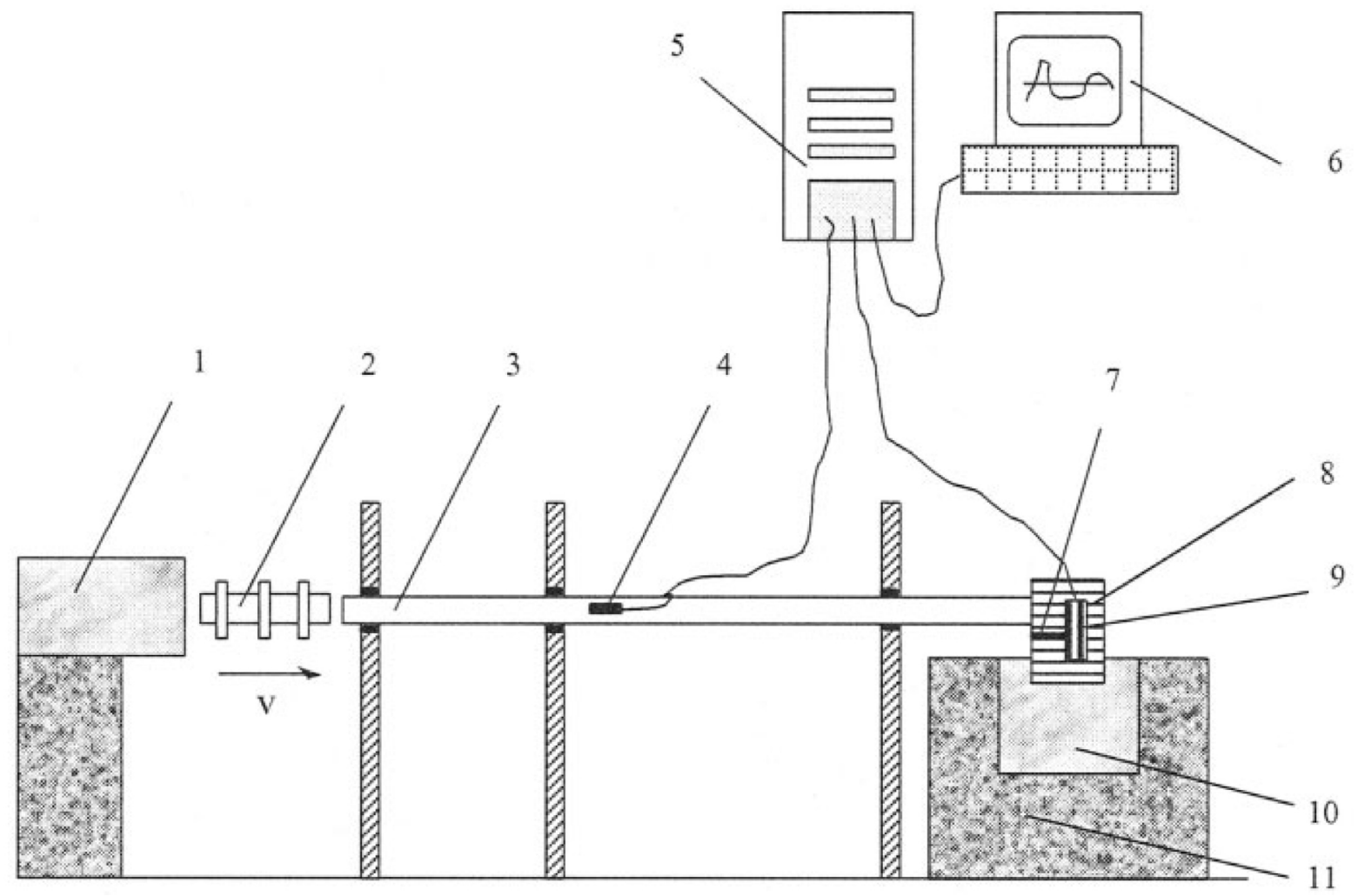

Figure 7. Schematic of HPB setup (mode II case). Note: Specimen and fixture dimensions are greatly exaggerated. 1, gas gun; 2, striker; 3, incident bar; 4, strain gage; 5, digital oscilloscope; 6, computer; 7, artificial crack; 8 , composite sample; 9 , crack detection gage (CDG); 10 , sample steel base; 11 , specimen supporter.

bar surface towards the strike bar in order to remove the spike-like dispersion wave, which usually occurs in highspeed impact tests based on the HPB configuration. From Figures 8 and 9, it can be seen that the reflected wave shape in the mode I testing case was more complicated than that in the mode II testing case. This was because after crack initiation the mode I sample was constrained by the support system, while the upper half-sample in the mode II testing case just simply broke off. The recorded test data showed that the crack initiation occurred in the very beginning of

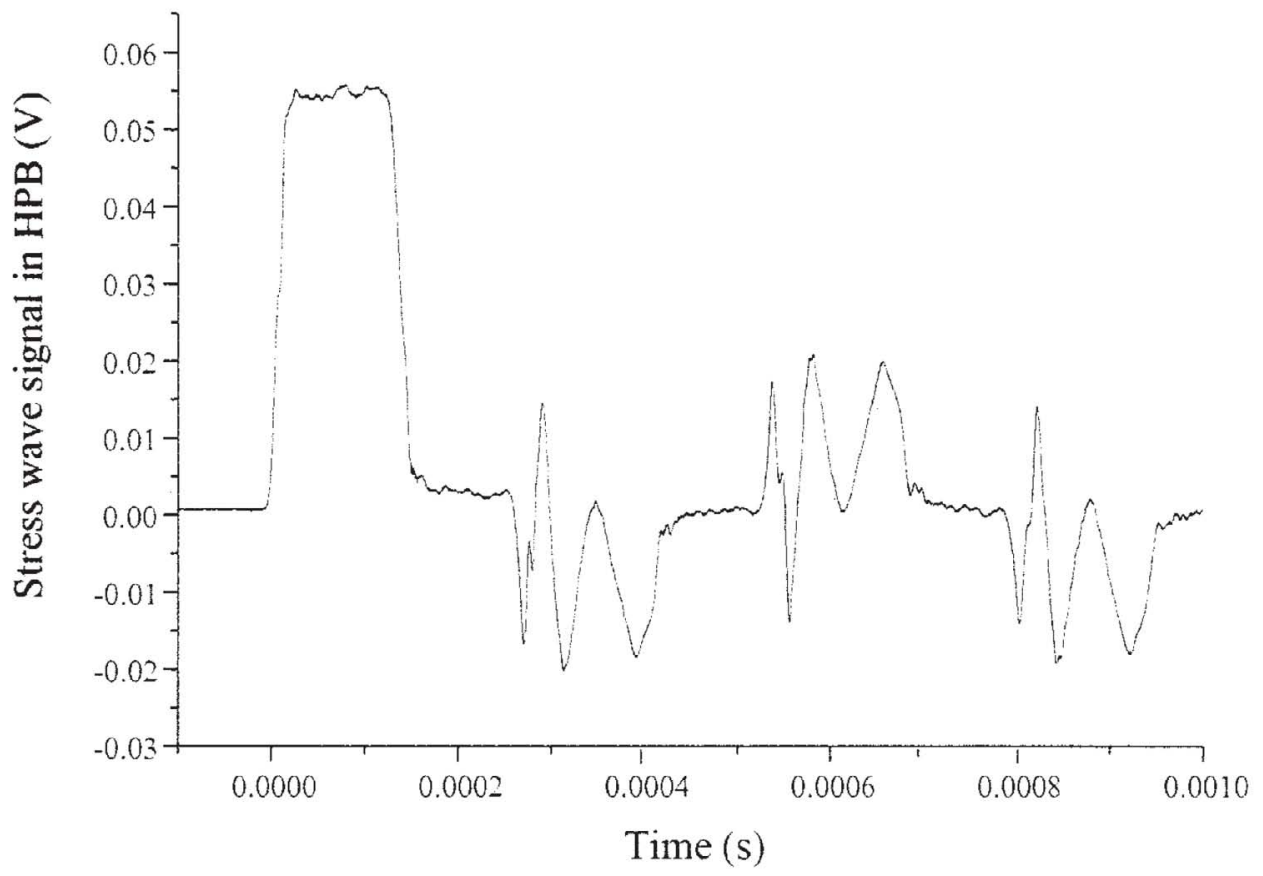

Figure 8. Typical stress wave signals in HPB (mode I case). 


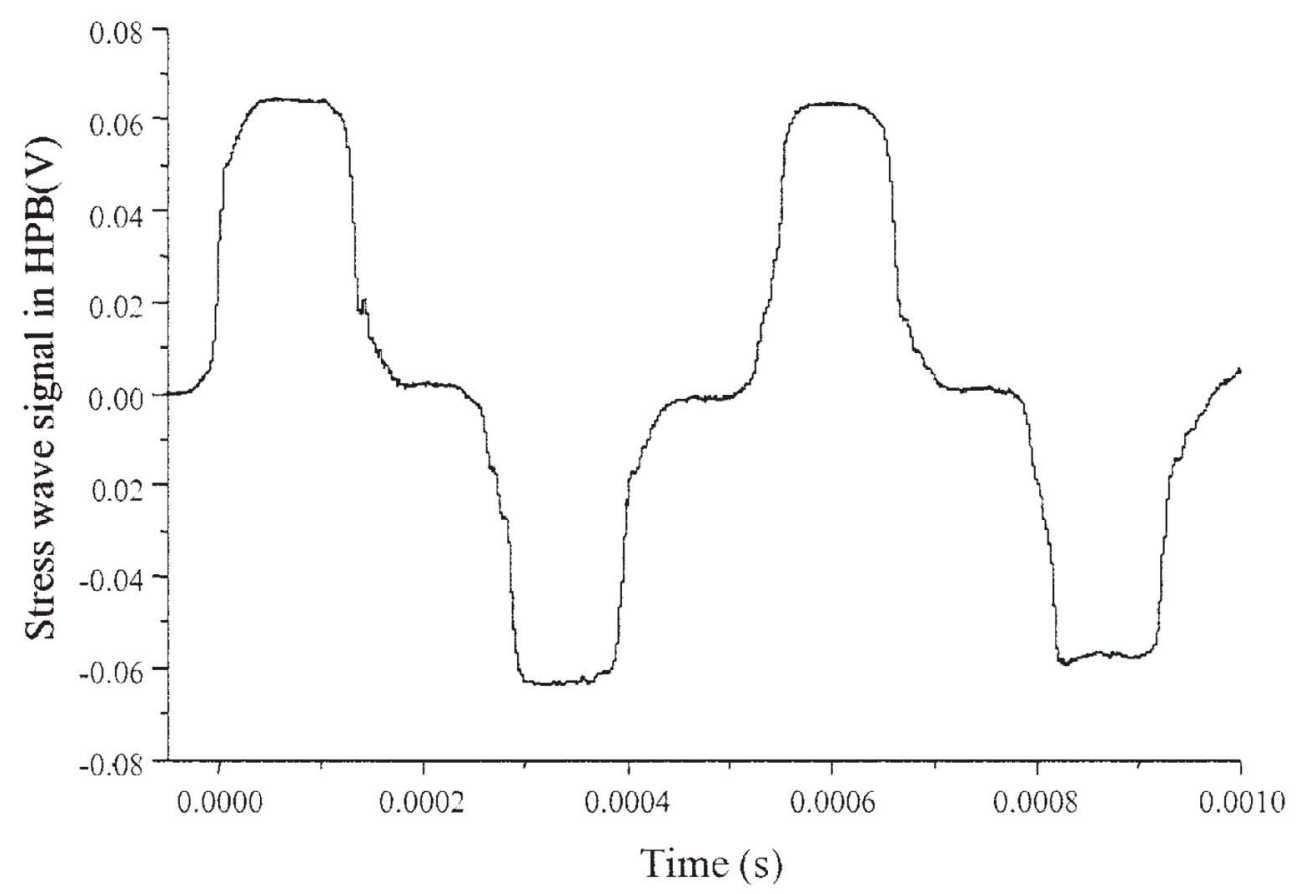

Figure 9. Typical stress wave signals in HPB (mode II case).

the impact event; thus, only the beginning portion of the complicated wave shape in the mode I testing case was used for data reduction.

Typical signals measured from the CDG in the mode I and mode II tests are shown in Figures 10 and 11, respectively. A step-jump pulse was observed in each case, corresponding to the crack initiation in the impact event. This value was used to find the critical DSIFs ( $\mathrm{K}_{\text {IDC }}$ and $\mathrm{K}_{\text {IIDC }}$ ) based on the FEA (ANSYS ${ }^{\circledR}$ ). The different step voltage values as shown in Figures 10 and 11 resulted from the different choices of the reference resistance values $R_{1}$ and $R_{2}$ shown in Figure 5, which did not affect the crack initiation time.

\section{Data Reduction and Evaluation of DSIFs}

The impact pressure acting on the sample surface can be calculated following the linear relation (Equation 1) and the strain difference between the incident wave and the

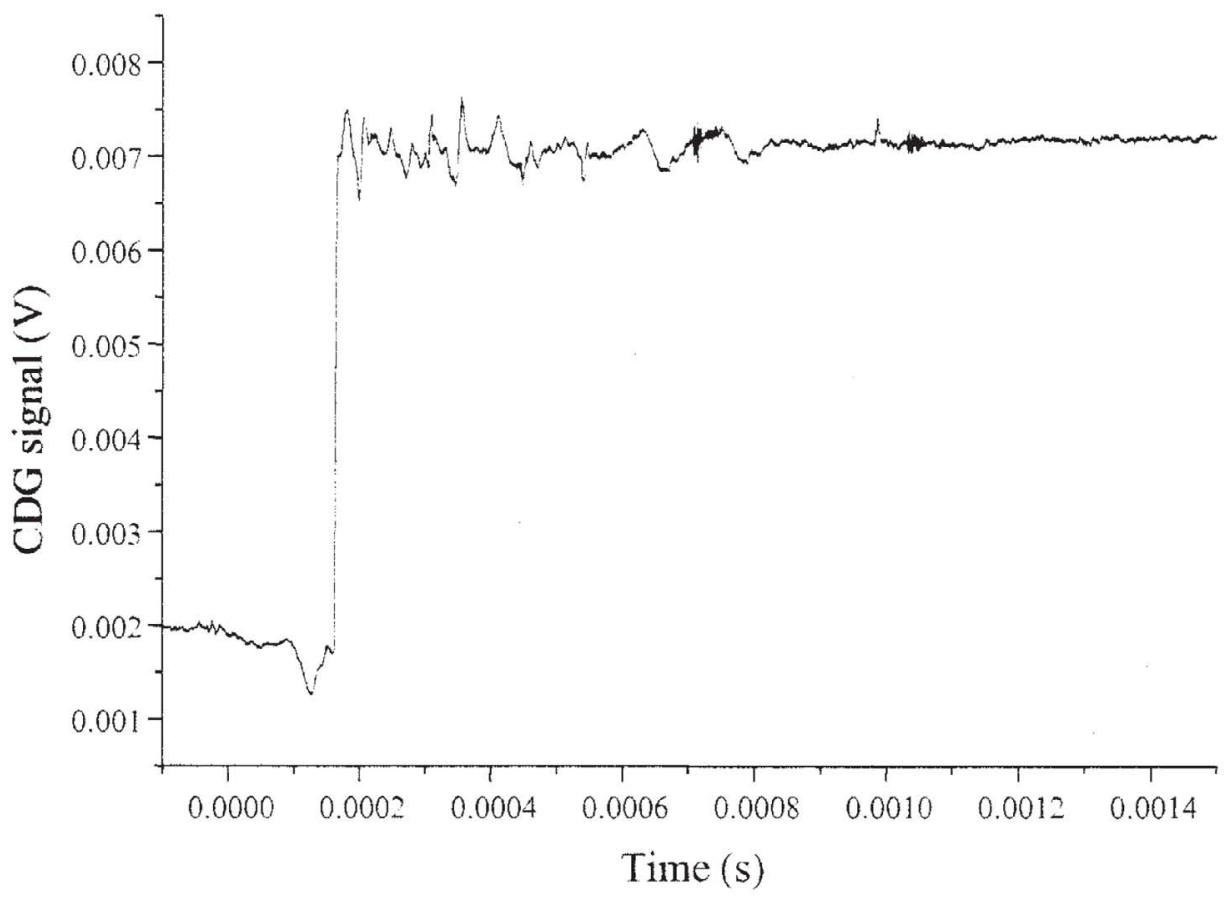

Figure 10. Typical crack initiation signals recorded in CDG circuit (mode I case). 


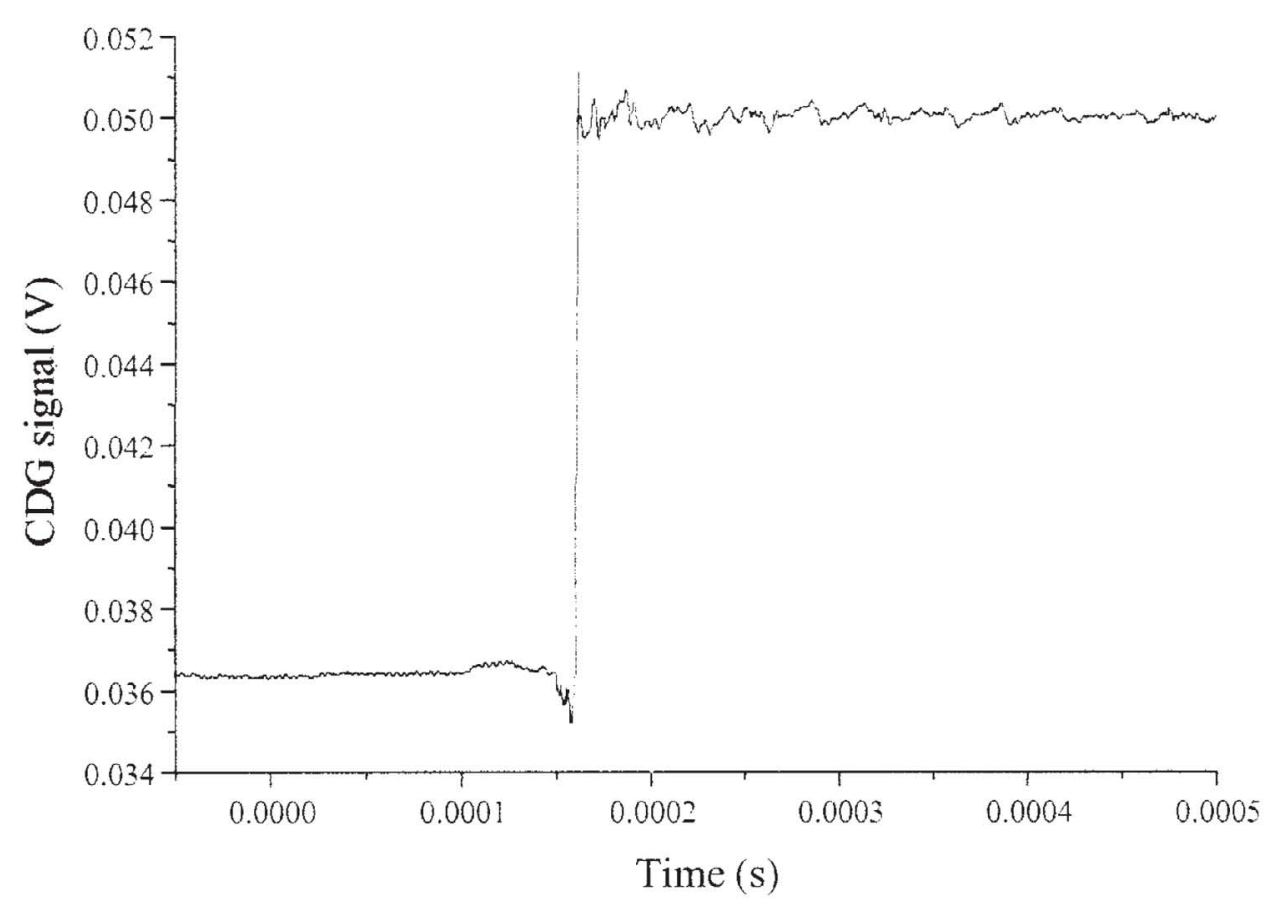

Figure 11. Typical crack initiation signals recorded in CDG circuit (mode II case).

first reflected wave. The cross-section of the HPB was circular with the diameter of $8 \mathrm{~mm}$, while the sample surface towards the HPB head was rectangular with the width of 12 $\mathrm{mm}$. In an attempt to apply two-dimensional FEA to simulate the dynamic fracture processes, the impact area was simplified as illustrated in Figure 12. This simplification did not result in significant deviation due to the wave propagation properties of unidirectional polymer composites.

Typical impact stresses acting on specimen surfaces in the mode I and mode II tests are plotted in Figures 13 and 14, respectively. By comparison with the crack initiation time from the CDG, it is found that the crack initiation for both mode I and mode II testing cases occurred after the first load peak, within an interval from $0.015 \mathrm{~ms}$ to 0.035 ms. This time is much shorter than the impact pulse duration, about $0.1 \mathrm{~ms}$ estimated from the striker length and also measured directly from the stress wave signals in the HPB. Thus, it can be concluded that the sample was under continuous loading during the crack initiation and growth. The wave propagation time in the sample was very short and therefore was negligible (wave speed: $\sim 6000 \mathrm{~m} / \mathrm{s}$, and the sample length: $20 \mathrm{~mm}$ ). The reduced impact stress was used for transient FEA simulation $\left(\mathrm{ANSYS}^{\circledR}\right.$ ).

Relationship Between SIF (KI/KII) and Crack Opening Displacements (CODs) in Anisotropic Materials

Dynamic SIF history before crack initiation was derived from the transient COD illustrated in Figure 15. Generally, numerical schemes used in FEA are based on the displacement conforming method; thus, strains at Gaussian integration points of each element are calculated from numer-
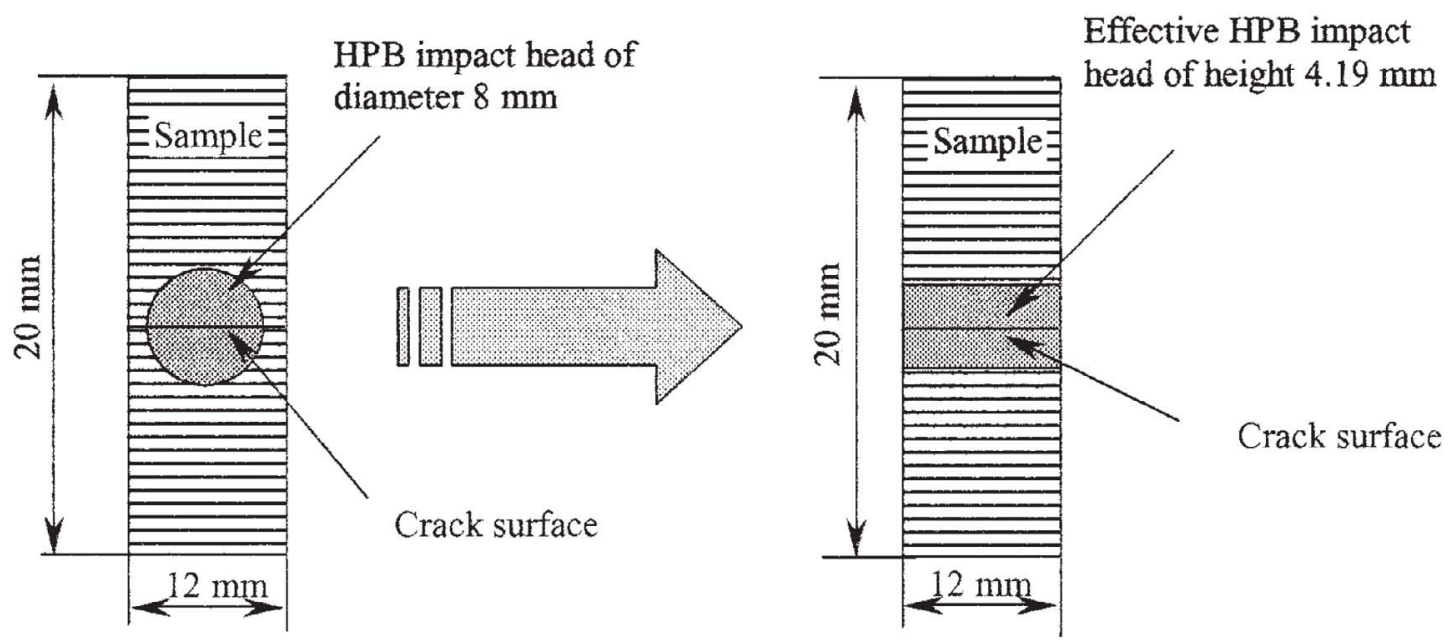

Figure 12. Schematic of HPB impact head simplification. 


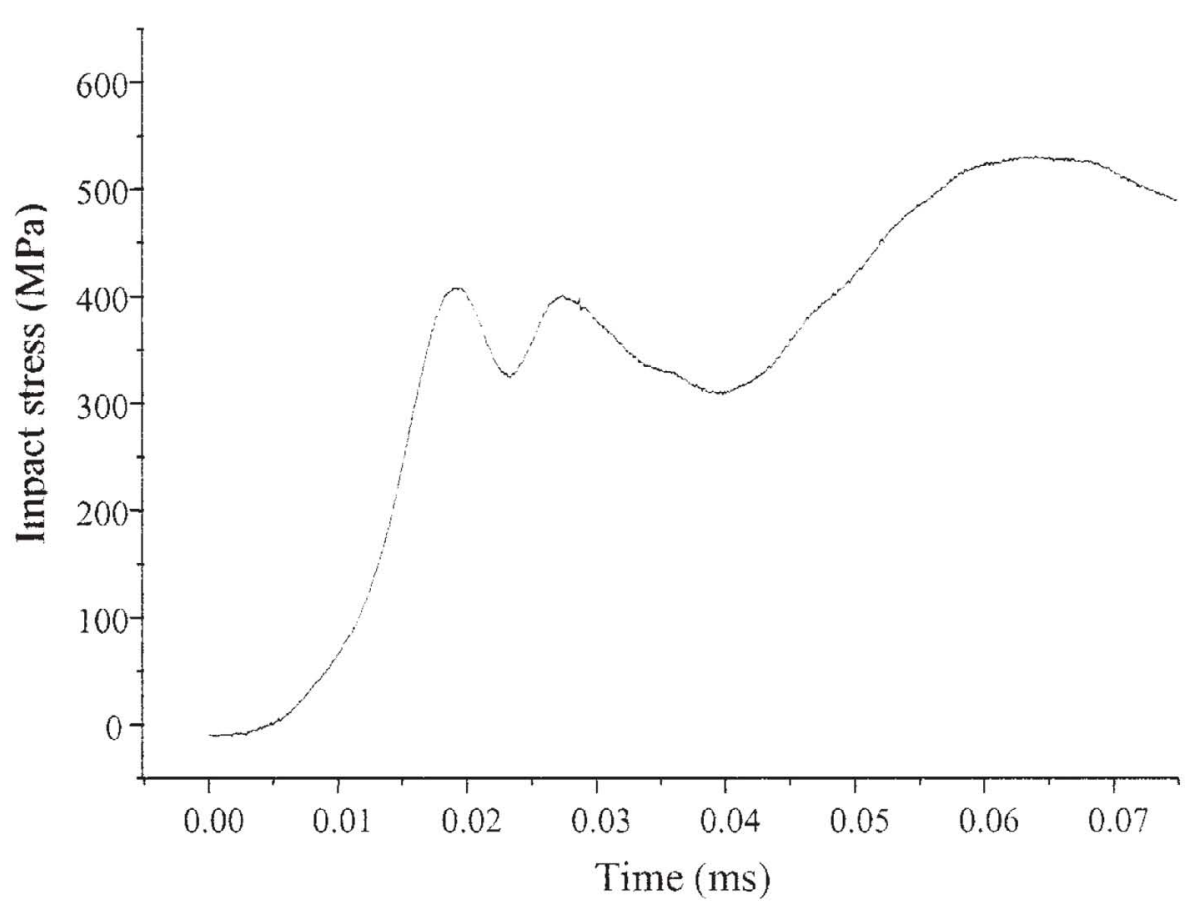

Figure 13. Typical impact stress acting on sample surface (mode I case).

ical derivative of the nodal displacements. Therefore, the numerical stress results by FEA generally have less accuracythan the numerical displacement results, especially near crack tips, notches, and corners, where stress singularities exist. Within the framework of linear elastic fracture mechanics (LEFM), numerical SIF and ERR of a static crack inelastic materials can be improved using the path-independent J-integral [31], which avoids the singular stress field near the crack tip by a contour integration far from the crack tip. In the case of a stationary crack under dynamic loading, there still exist some dynamic path-independent integrals. However, these path integrals involve area integrations inside the contour; thus, the singular stress field near the crack tip cannot be avoided. In dynamic fracture mechanics $[32,33]$, it has been proved that under dynamic loading the asymptotic stress field near the tip of a stationary

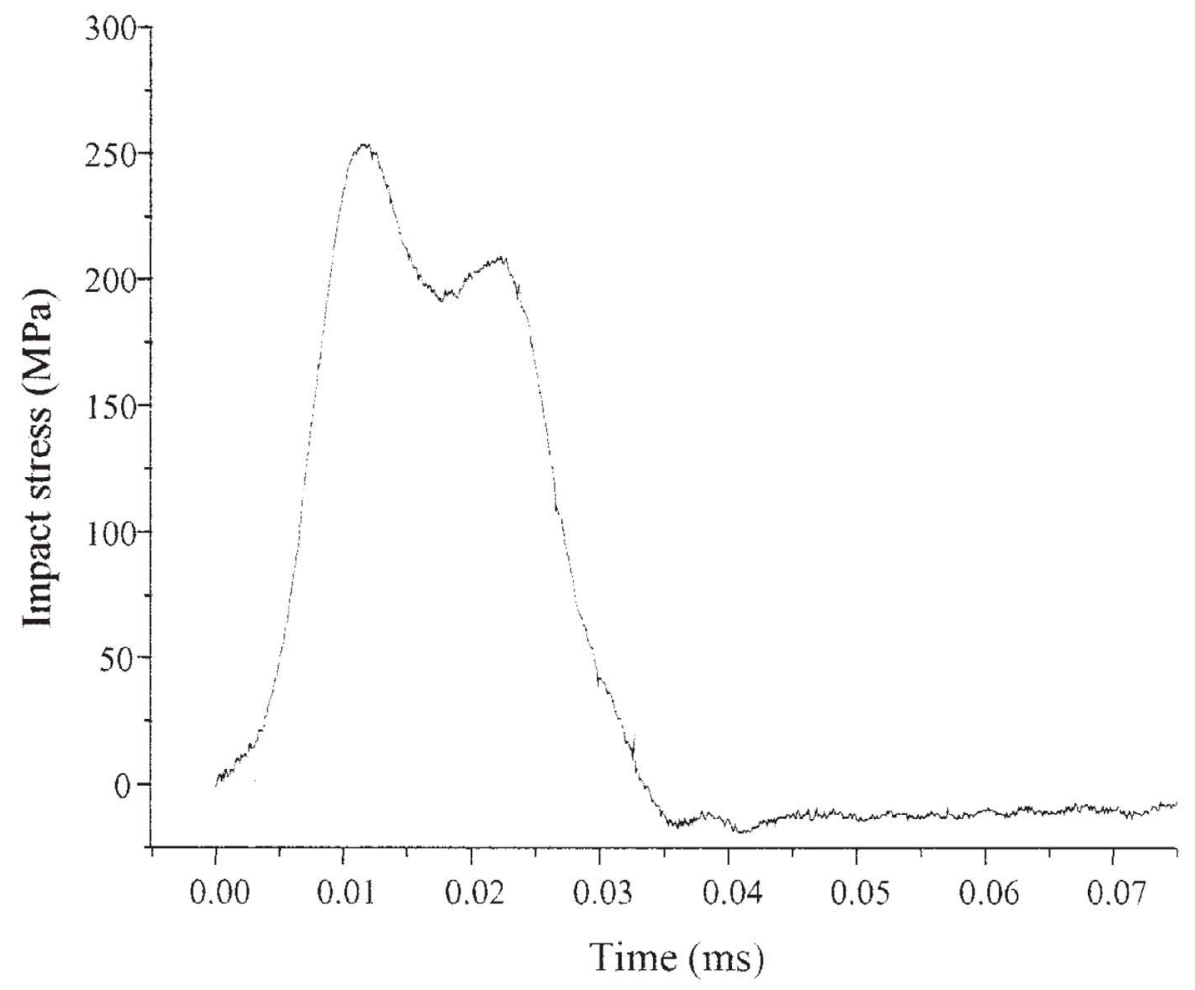

Figure 14. Typical impact stress acting on sample surface (mode II case). 


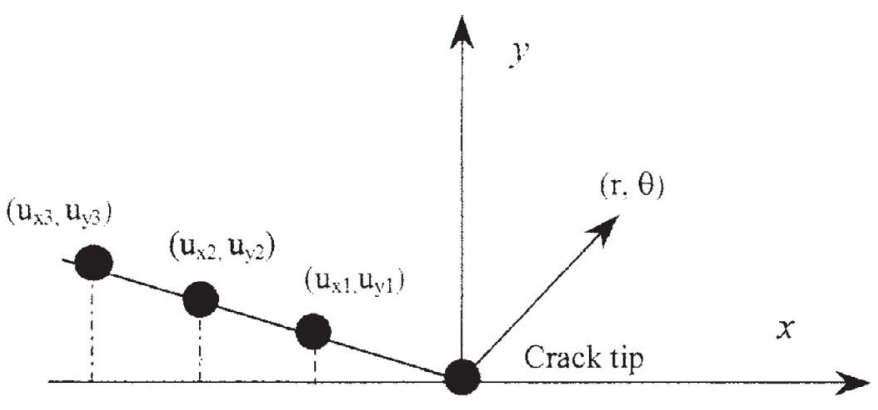

Figure 15. Schematic of COD.

crack in elastic medium still retains the singular profile similar to the static one. Thus, the DSIFs can be extracted using the transient COD based on numerical schemes in computational fracture mechanics [34].

Here we first consider a stationary mode I crack in a general anisotropic material under dynamic loading. Based on LEFM of anisotropic materials [35], the dynamic asymptotic displacement $u_{\mathrm{y}}(t)$ near the crack tip is assumed to be the same form as that of the static loading case such that

$$
\begin{aligned}
u_{y}(t)=\frac{K_{\text {ID }}(t)}{\sqrt{\pi}} \sqrt{2 r} \operatorname{Re}[ & \frac{1}{\lambda_{1}-\lambda_{2}}\left(\lambda_{1} q_{2} \sqrt{\cos \theta+\lambda_{2} \sin \theta}\right. \\
& \left.\left.-\lambda_{2} q_{1} \sqrt{\cos \theta+\lambda_{1} \sin \theta}\right)\right] .
\end{aligned}
$$

Here

$$
q_{j}=S_{11} \lambda_{j}^{2}+\frac{S_{22}}{\lambda_{j}}-S_{26}
$$

and $\lambda_{j}(j=1,2)$ are the complex roots with the positive imaginary parts of the eigenvalue equation:

$$
S_{11} \lambda^{4}-2 S_{16} \lambda^{3}+\left(2 S_{12}+S_{66}\right) \lambda^{2}-2 S_{26} \lambda+S_{22}=0,
$$

where $S_{i j}(i=1,2 ; j=1,2,6)$ are the elastic compliance elements.

In the case of unidirectional composite materials, Sij reduce to

$$
\begin{aligned}
& S_{11}=1 / E_{1}, \quad S_{12}=-v_{12} / E_{1}=-v_{21} / E_{2}, \\
& S_{22}=1 / E_{2}, \quad S_{16}=0, \quad S_{66}=1 / G_{12},
\end{aligned}
$$

and the complex roots of Equation 4 have only positive imaginary parts:

$$
\begin{aligned}
& \lambda_{1}=i\left\{\frac{\left(2 S_{12}+S_{66}\right)+\left[\left(2 S_{12}+S_{66}\right)^{2}-8 S_{11} S_{22}\right]^{1 / 2}}{2 S_{11}}\right\}^{1 / 2}, \\
& \lambda_{2}=i\left\{\frac{\left(2 S_{12}+S_{66}\right)-\left[\left(2 S_{12}+S_{66}\right)^{2}-8 S_{11} S_{22}\right]^{1 / 2}}{2 S_{11}}\right\}^{1 / 2} .
\end{aligned}
$$

The COD is obtained by setting $\theta=\pi$ in Equation 2 as

$$
\begin{aligned}
u_{y}(t)=\frac{K_{I D}(t)}{\sqrt{\pi}} \sqrt{2 r} & \operatorname{Re}\left[\frac{i\left(\lambda_{1} q_{2}-\lambda_{2} q_{1}\right)}{\lambda_{1}-\lambda_{2}}\right] \\
& =\frac{K_{I D}(t)}{\sqrt{\pi}} \sqrt{r} \sqrt{S_{11} S_{22}} \operatorname{Im}\left(\lambda_{1}+\lambda_{2}\right),
\end{aligned}
$$

and the ERR can be evaluated based on Reference 35 such that

$$
G_{I}=K_{I}^{2}\left(\frac{S_{11} S_{22}}{2}\right)^{1 / 2}\left[\left(\frac{S_{22}}{S_{11}}\right)^{1 / 2}+\frac{2 S_{12}+S_{66}}{2 S_{11}}\right]^{1 / 2} .
$$

In the case of mode II crack, the asymptotic dynamic displacement $u_{x}(t)$ near the crack tip can be expressed as

$$
\begin{array}{r}
u_{x}(t)=\frac{K_{I I D}(t)}{\sqrt{\pi}} \sqrt{2 r} \operatorname{Re}\left[\frac { 1 } { \lambda _ { 1 } - \lambda _ { 2 } } \left(p_{2} \sqrt{\cos \theta+\lambda_{2} \sin \theta}\right.\right. \\
\left.\left.-p_{1} \sqrt{\cos \theta+\lambda_{1} \sin \theta}\right)\right],
\end{array}
$$

where

$$
p_{j}=S_{11} \lambda_{j}^{2}+S_{12}-S_{16} \lambda_{j} .
$$

The sliding displacement is obtained by setting $\theta=\pi$ in Equation 9 as

$$
\begin{aligned}
u_{x}(t)=\frac{K_{I I D}(t)}{\sqrt{\pi}} \sqrt{2 r} & \operatorname{Re}\left[\frac{i\left(p_{2}-p_{1}\right)}{\lambda_{1}-\lambda_{2}}\right] \\
& =\frac{K_{I I D}(t)}{\sqrt{\pi}} \sqrt{2 r} S_{11} \operatorname{Im}\left(\lambda_{1}+\lambda_{2}\right),
\end{aligned}
$$

and the corresponding ERR is evaluated as in Reference 35

$$
G_{I I}=K_{I I}^{2} \frac{S_{11}}{\sqrt{2}}\left[\left(\frac{S_{22}}{S_{11}}\right)^{1 / 2}+\frac{2 S_{12}+S_{66}}{2 S_{11}}\right]^{1 / 2} .
$$

\section{FEM Simulation of Impact Fracture Tests}

A transient two-dimensional FEA (ANSYS ${ }^{\circledR}$ ) involving implicit algorithm was conducted to determine the DSIFs $\left(\mathrm{K}_{\mathrm{IDC}}\right.$ and $\left.\mathrm{K}_{\mathrm{IIDC}}\right)$ under impact loading. Implicit algorithm was suitable for this case due to the relatively smooth loading history. Cracks were assumed stationary during the whole simulation; thus, the valuable numerical results were those before the CDG breakage. In an attempt 


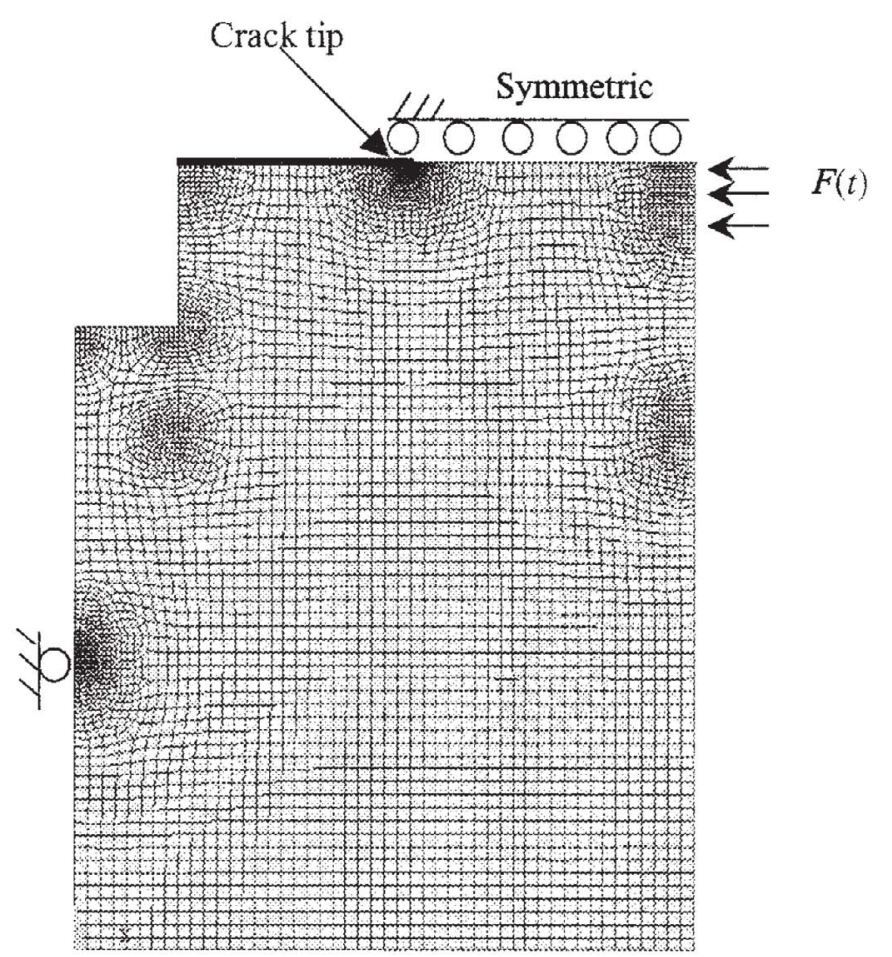

Figure 16. Half-structural FEM mesh and boundary conditions (mode I case).

to simplify the numerical simulation, the specimen fixture bases were assumed as rigid bodies, and the composite samples and the steel-bases were considered as linearly elastic materials. The elastic properties are $E_{1}=135 \mathrm{GPa}$, $E_{2}=E_{3}=8.5 \mathrm{GPa}, \mathrm{G}_{12}=\mathrm{G}_{13}=4.7 \mathrm{GPa}, v_{12}=v_{13}=0.34$, and the mass density $\rho=1,570 \mathrm{~kg} / \mathrm{m}^{3}$ for the graphite-fiber/ epoxy composite samples (orthotropic material), and $E=$ $200 \mathrm{GPa}, v=0.28$, and $\rho=7,800 \mathrm{~kg} / \mathrm{m}^{3}$ for the steel bases (isotropic material). A half-structural FEA-model was utilized to represent the structural and loading symmetries of the mode I testing case, as shown in Figure 16, and an entire structural FEA-model was used to simulate the impact-shearing fracture test, as shown in Figure 17. Fournode isoparametric linear element PLANE42 (ANSYS ${ }^{\circledR}$ ) was selected for this simulation. The minimum mesh size near the crack tip was $0.01 \mathrm{~mm}$ and the maximum element size was $0.4 \mathrm{~mm}$.

DSIFs ( $\mathrm{K}_{\mathrm{ID}}$ and $\left.\mathrm{K}_{\mathrm{IID}}\right)$ for the current mode I and mode II cracks were extrapolated based on Equations 7 and 11 and the transient CODs of three nearest nodes behind the crack tip as shown in Figure 15. Numerical experiments showed creditable convergence of the numerical DSIFs based on this scheme. DSIF results of two typical mode I samples and one typical mode II sample are plotted in Figures 18 and 19, respectively. Since the impact-shearing test was based on unsymmetrical specimen design, the interaction between the specimen and the HPB was complicated. In general, frictional sliding, contact separation, and specimen rotation might have taken place before crack initiation. During this numerical simulation, the contact was assumed perfect and no contact separation and sliding were considered. The DSIF

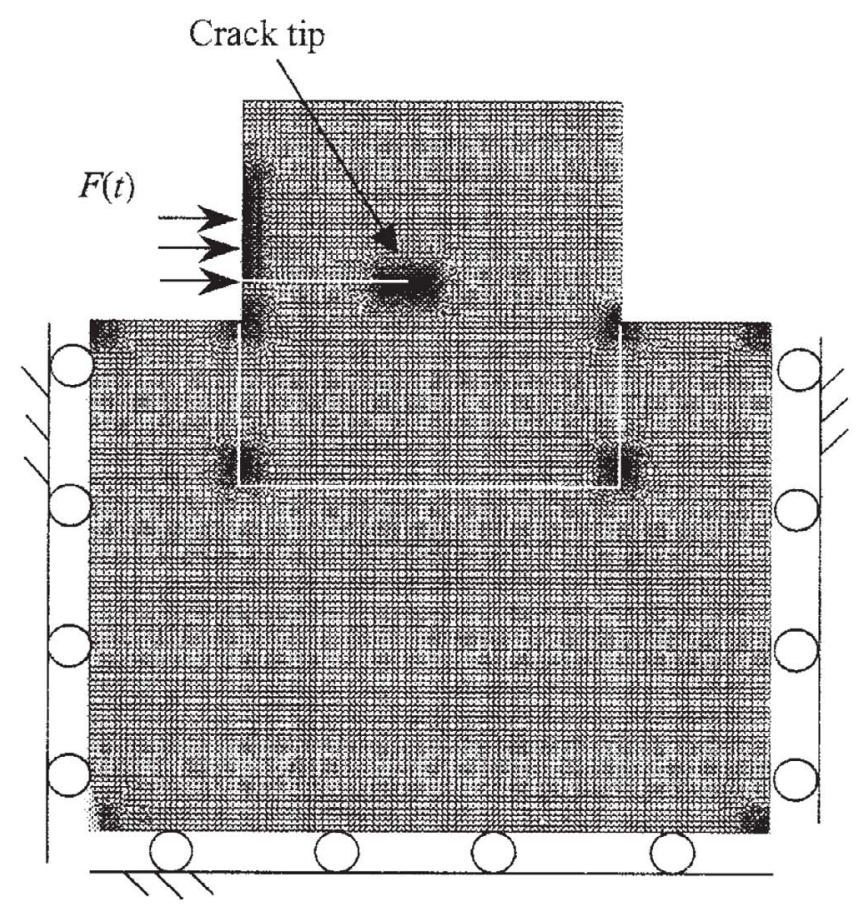

Figure 17. Structural FEM mesh and boundary conditions (mode II case).

mode separation in the mode II testing case was based on Equations 7 and 11 and the transient numerical CODs.

\section{Evaluation of Critical DSIF}

Critical DSIF values for the mode I and mode II tests were determined by the SIF values at the crack initiation time in Figures 18 and 19. The recorded crack initiation time after impact and corresponding critical DSIF values of two typical mode I specimens are tabulated (Table 2). The mode II fracture occurred very close to the peak value of the separated mode II SIF shown in Figure 19, where it can be seen that the mode-mixture ratio is very low. Thus, the separated mode II SIF value at crack initiation can be considered as its critical value $\mathrm{K}_{\text {IIDC }}$ (Table 3 ).

Analysis of the mode I test results shows that crack initiation durations (0.0175-0.0345 ms) were within the impact loading duration of $0.1 \mathrm{~ms}$. Thus, the mode I specimen was always under loading before the crack initiation. During this period, the SIF grew to the critical value. Numerical results show that the critical DSIF value $\left(\mathrm{K}_{\mathrm{IDC}}\right)$ was about 80 $90 \%$ of the static one obtained by the quasi-static DCB delamination test.

In the mode II testing case, the crack initiation occurred near the peak $\mathrm{K}_{\mathrm{IID}}$ value. The mode II crack began to grow after its initiation duration around $0.025 \mathrm{~ms}$. This duration is also within the range of the impact loading duration (0.1 $\mathrm{ms}$ ). Thus, the mode II specimen was always under loading before the crack initiation. Numerical results show that the critical DSIF value ( $\mathrm{K}_{\mathrm{IIDC}}$ ) was close to the static one obtained by means of quasi-static ENF delamination test. 


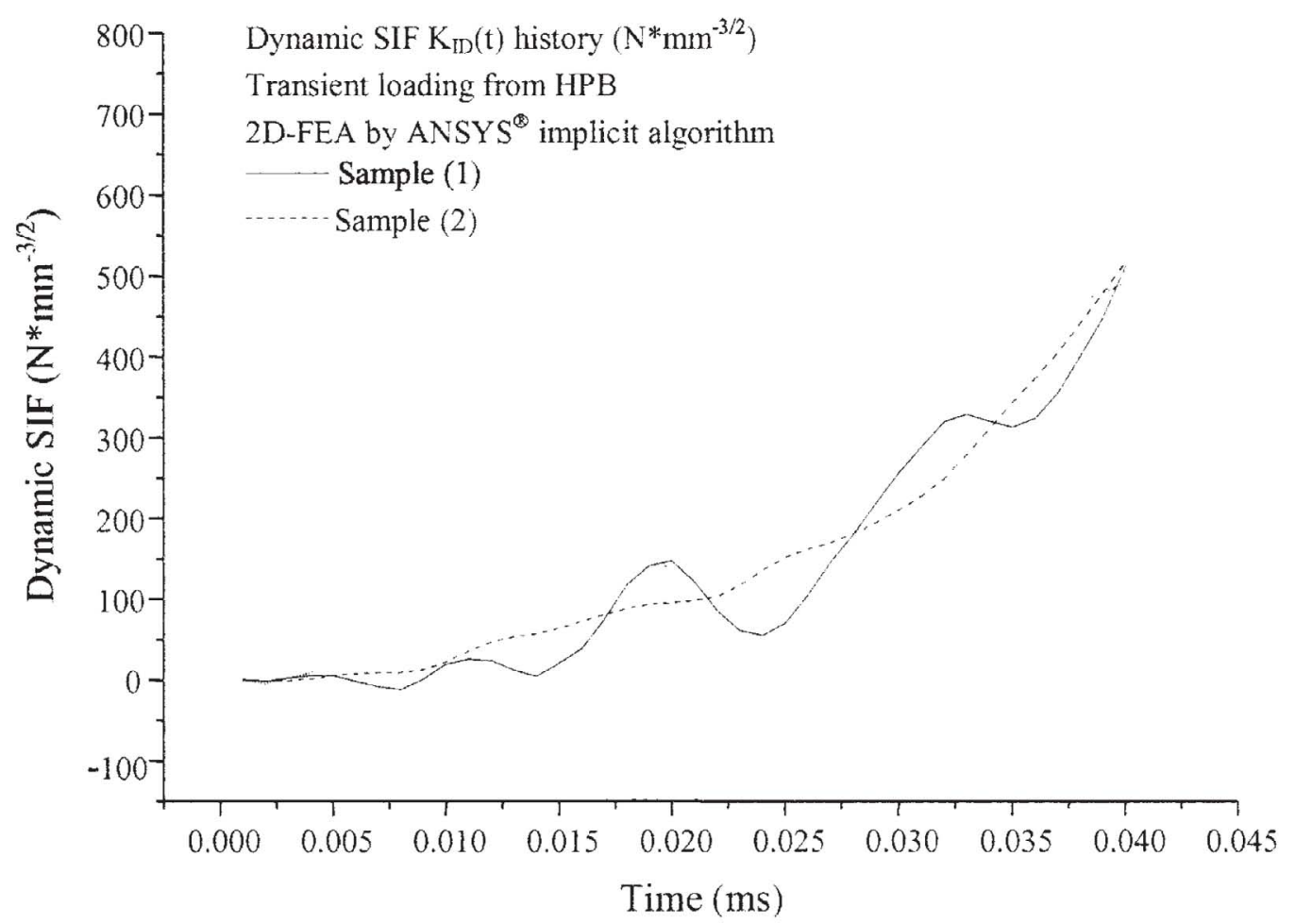

Figure 18. Dynamic SIF history $\mathrm{K}_{\mathrm{ID}}(\mathrm{t})$ (mode I case).

However, experimental results also indicated a relatively high scatter of the measured crack initiation time and impact forces, which highly depended upon pre-crack geometry, test setup, HPB/sample contact conditions, and data recording system. There existed some uncertainties during signal sampling, and the real contact time between the HPB headand specimen surface was approximated, as shown in Figure 20. The crack initiation time may be also affected by the CDG strand deformation, strand width, and biased location with respect to the crack tip. From Figure 18 it can be found that the impact loading also excited the natural modes of the specimens.

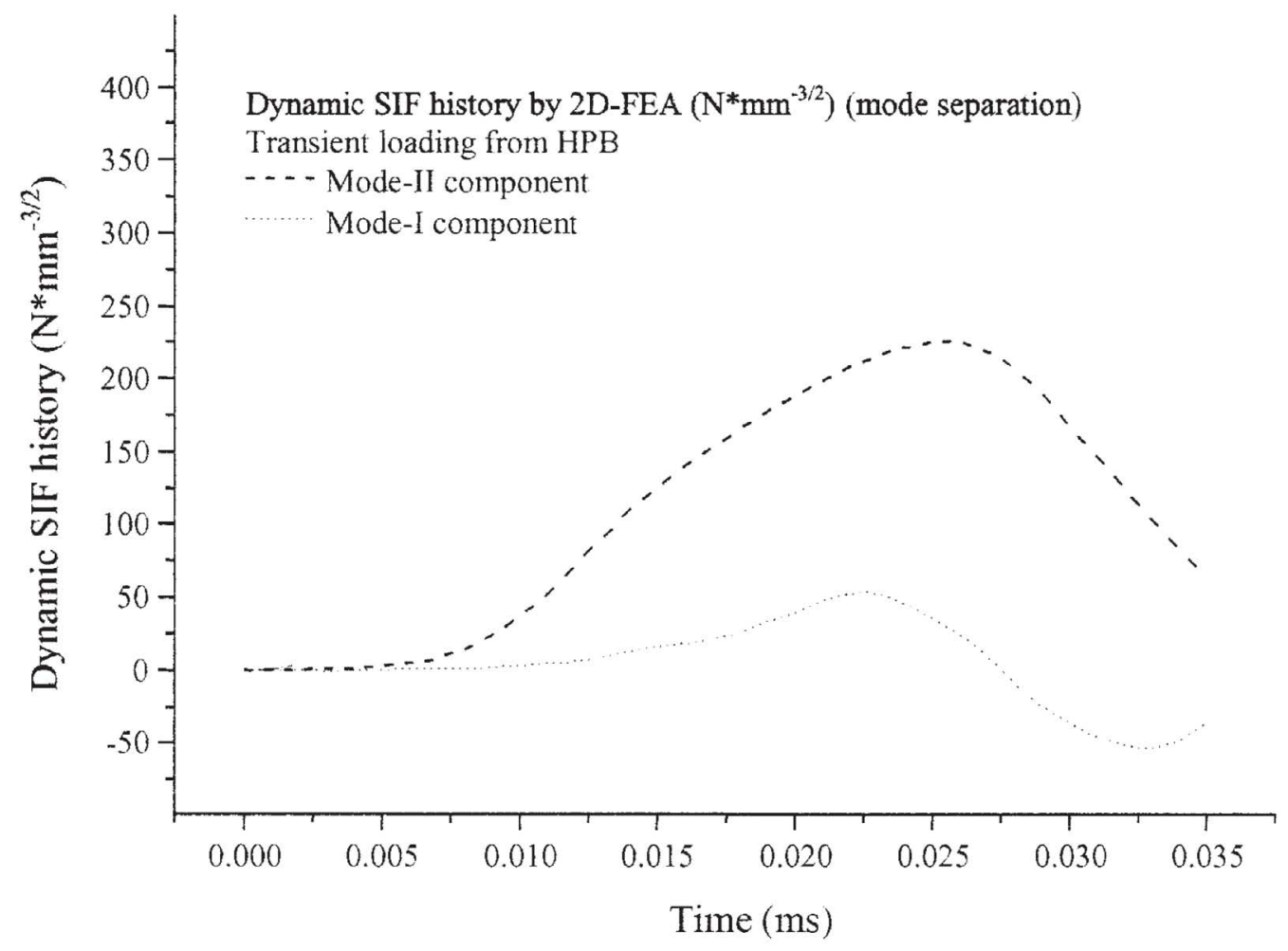

Figure 19. Dynamic SIF history $\mathrm{K}_{\text {IID }}(\mathrm{t})$ (mode II case). 
Table 2. Crack initiation time and critical DSIF values.*

\begin{tabular}{lcc}
\hline No. & Crack initiation time $\mathrm{t}_{0}(\mathrm{~ms})$ & $\begin{array}{c}\text { Critical SIF K } \\
\left(\mathrm{N} \cdot \mathrm{mm}^{-3 / 2}\right)^{\mathrm{a}}\end{array}$ \\
\hline Sample (1) & 0.0245 & 81.3 \\
Sample (2) & 0.0175 & 93.7 \\
\hline
\end{tabular}

*Mode I case.

a Static critical $\mathrm{K}_{\mathrm{IC}}=102.7 \mathrm{~N} \cdot \mathrm{mm}^{-3 / 2}$ based on DCB test configuration.
Table 3. Separation of critical DSIF value.*

\begin{tabular}{ccc}
\hline & $\begin{array}{c}\text { Mode II SIF } \\
\text { part }\left(\mathrm{N} \cdot \mathrm{mm}^{-3 / 2}\right)\end{array}$ & $\begin{array}{c}\text { Mode I SIF } \\
\text { part }\left(\mathrm{N} \cdot \mathrm{mm}^{-3 / 2}\right)^{\mathrm{a}}\end{array}$ \\
\hline Typical sample & 225.0 & 55.6 \\
\hline
\end{tabular}

*Mode II case.

a Static critical $\mathrm{K}_{\mathrm{IIC}}=211.3 \mathrm{~N} \cdot \mathrm{mm}^{-3 / 2}$ based on ENF test configuration.

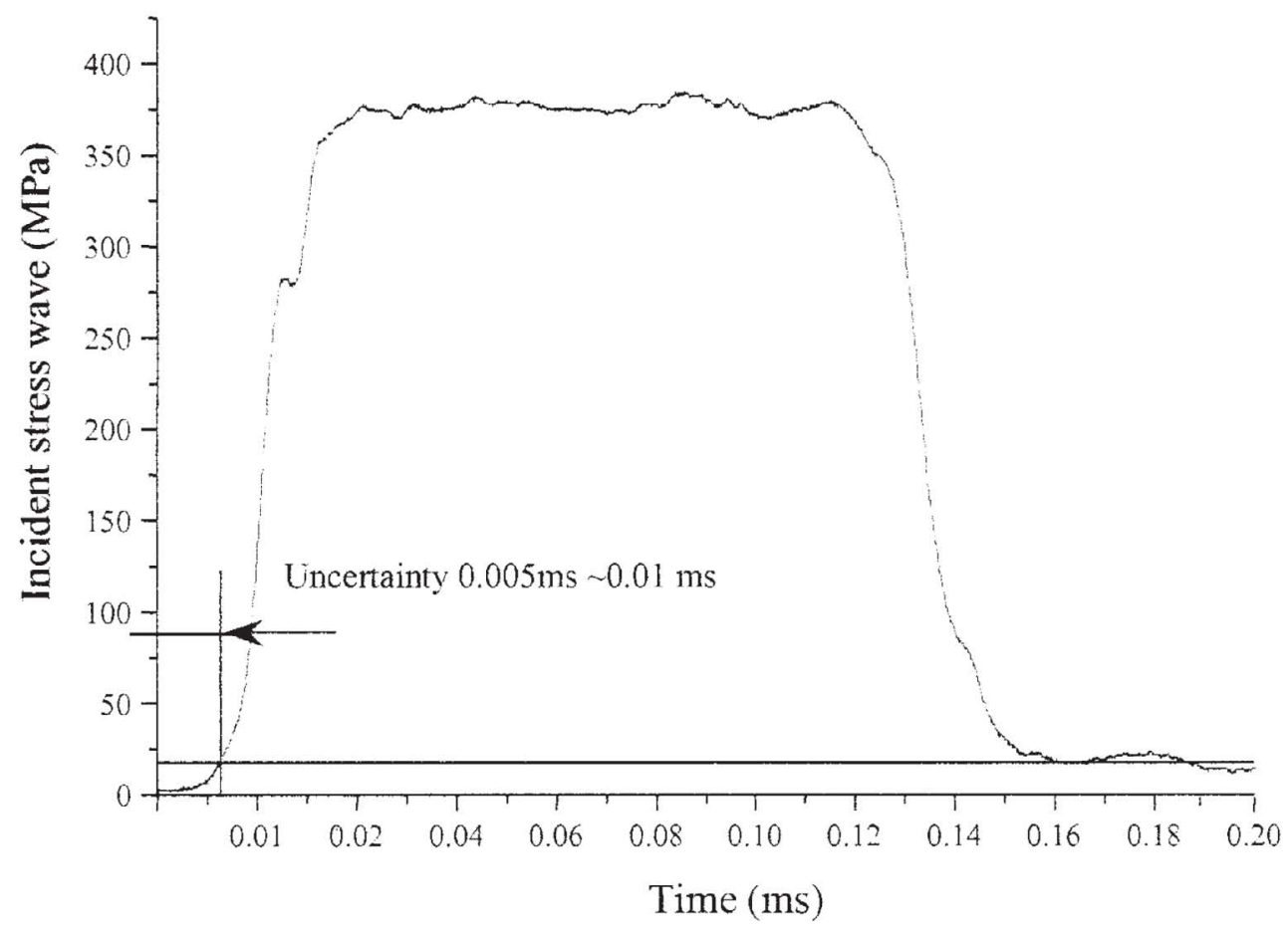

Figure 20. Schematic of uncertainty of impact evaluation.

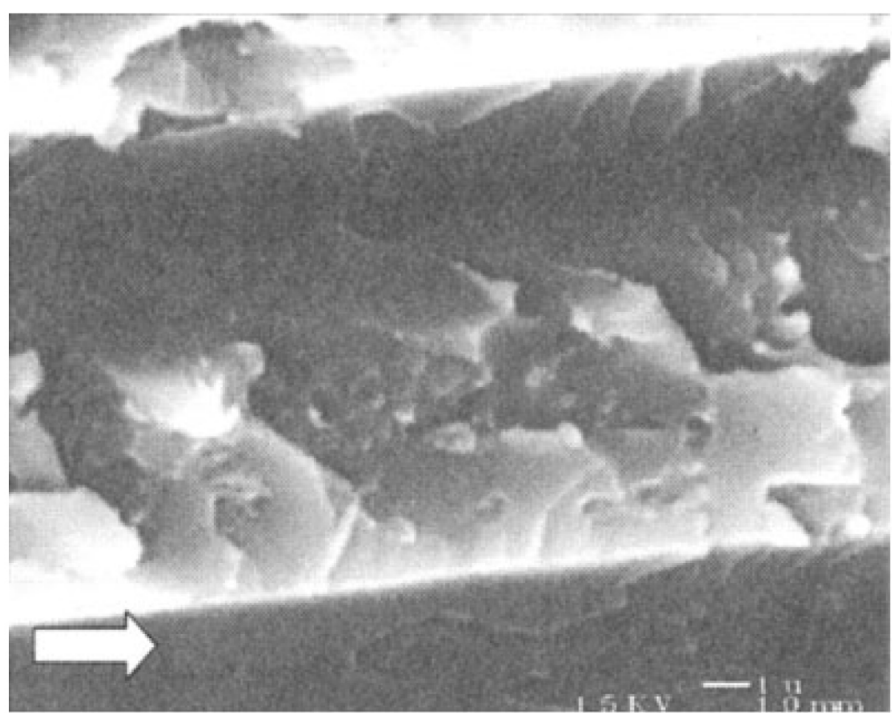

(a)

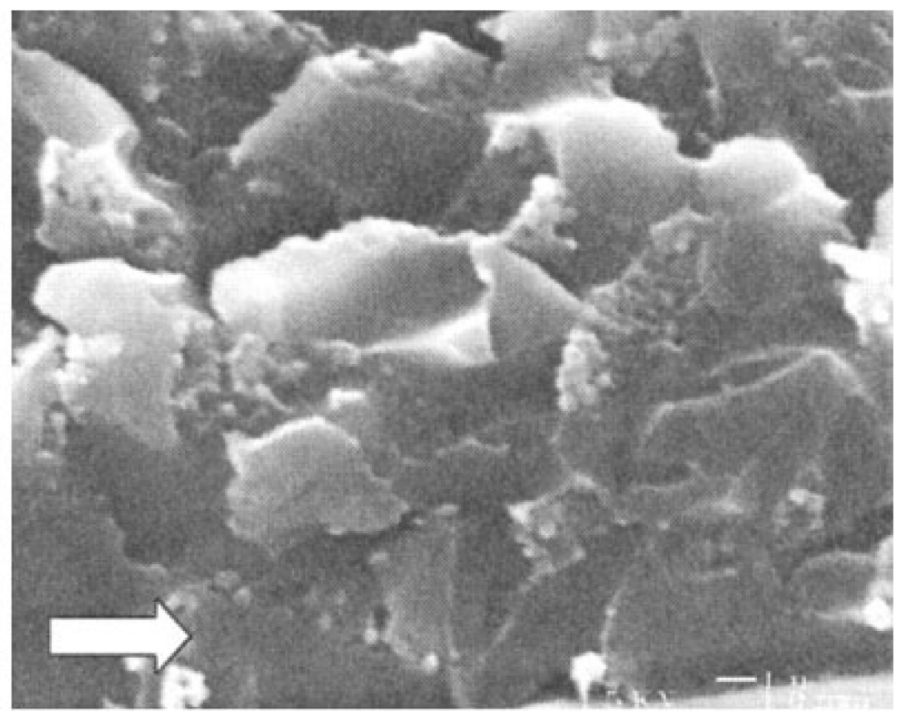

(b)

Figure 21. Matrix brittle failure (mode I case). 


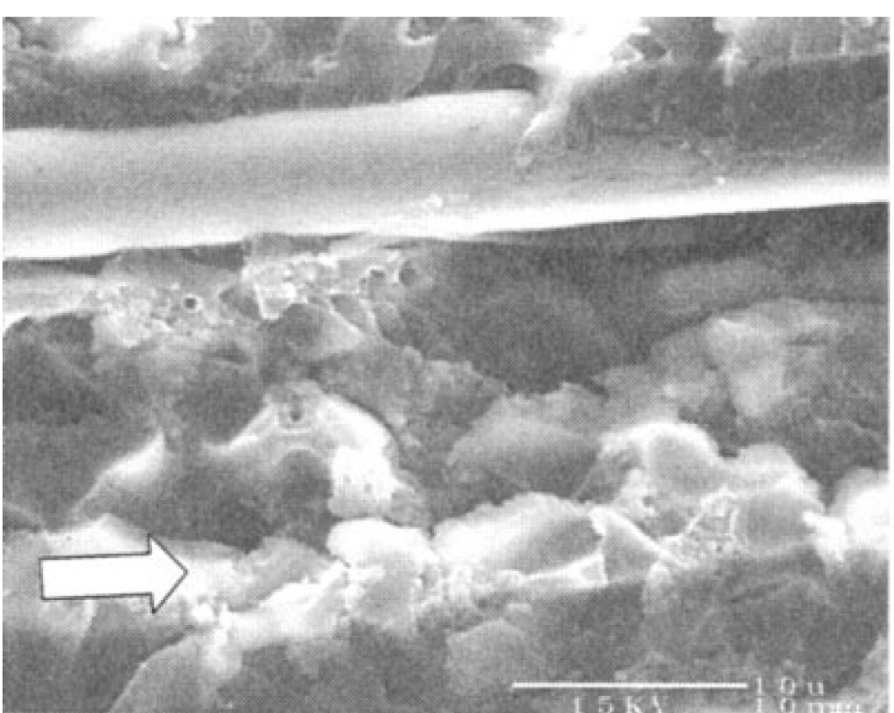

(a)

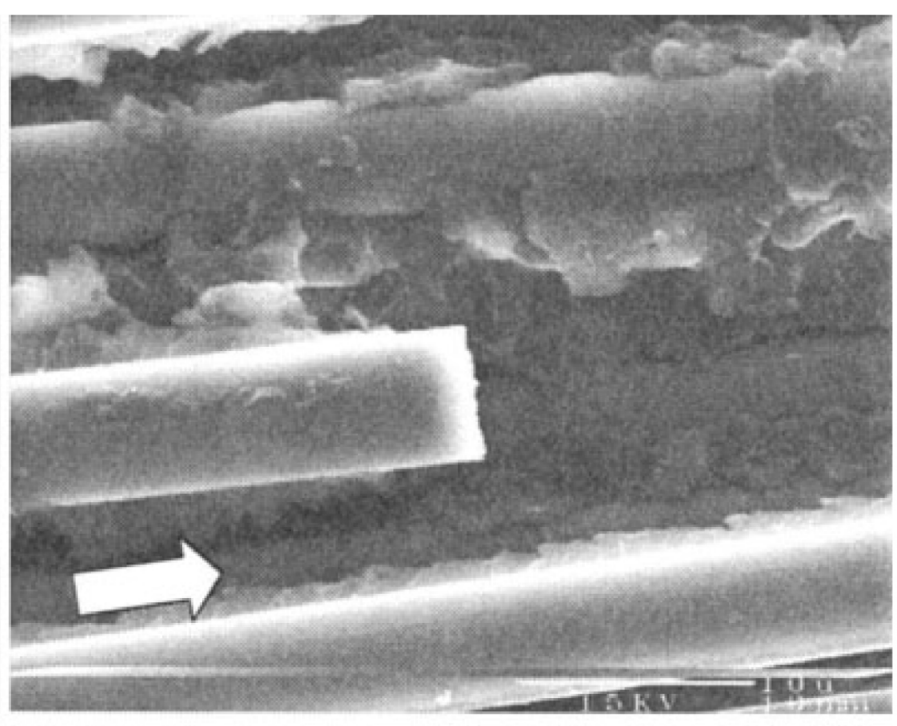

(b)

Figure 22. Fiber breakage (mode I case). Graphite fiber diameter: $\sim 7 \mu \mathrm{m}$.

\section{SEM Fractographic Analysis}

Crack surfaces of failed specimens looked very smooth by naked eyes. A detailed SEM fractography was performed to explore the failure microscopic mechanisms. For mode I testing case, the typical fracture surfaces after impact test are shown in Figures 21 and 22, where arrows indicate the crack propagation directions, respectively. The SEM fractographic results show that the general features of the crack surfaces are consistent with brittle matrix fracture as shown in Figure 21a and b. Fiber/matrix debonding (Figure 22a and b) and fiber breakage (Figure 22b) were also observed. During dynamic crack propagation, interfacial failure occurred in a brittle mode, and fiber bridging and pullout were not usually observed due to the high loading rate. These observations are different from those observed in static mode I delamination tests, where fiber bridging dominates the fracture process. As a result, the measured critical DSIF value $\left(\mathrm{K}_{\mathrm{IDC}}\right)$ was lower than the static one from the current study $(80-90 \%)$.

In the mode II testing case, SEM fractographic results show quite different crack surface profiles. Typical crack surfaces in Figures 23 and 24 show that the general failure features consist of fiber debonding due to fiber sliding under dynamic shear loading, and matrix brittle shear failure. Under high rate shear loading, graphite fibers even exhibited localized shear failure, as shown in Figure 24, which was not observed in quasi-static and fatigue delamination tests.

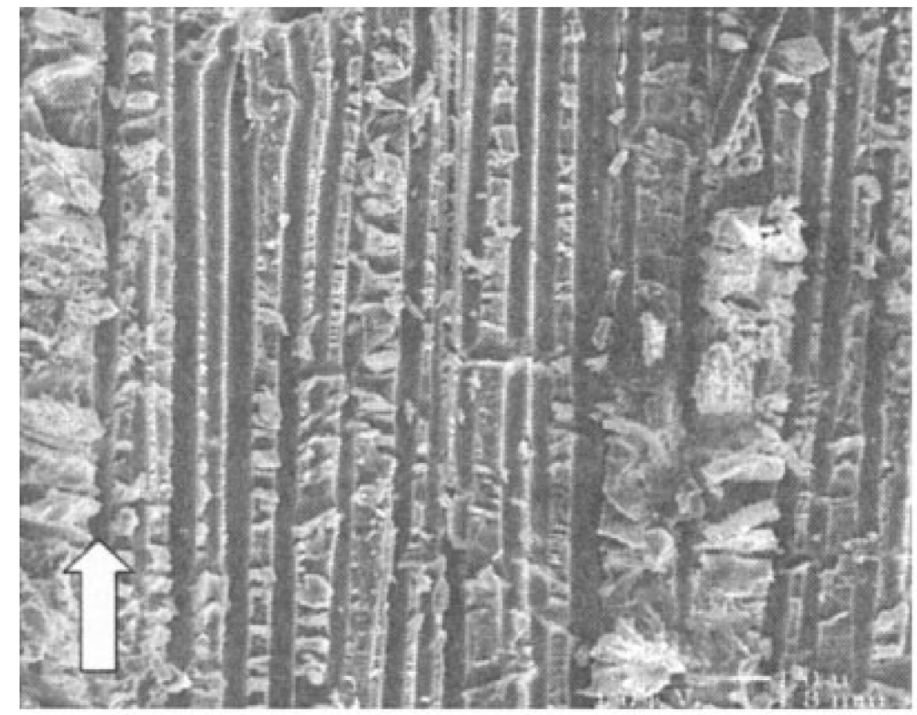

(a)

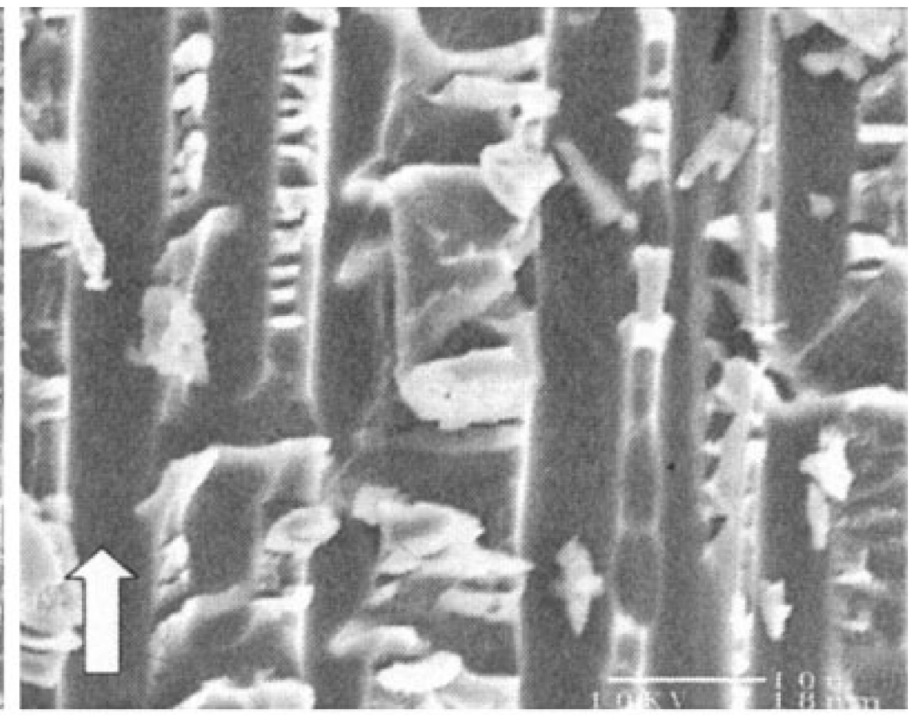

(b)

Figure 23. Matrix shearing failure (mode II case). 


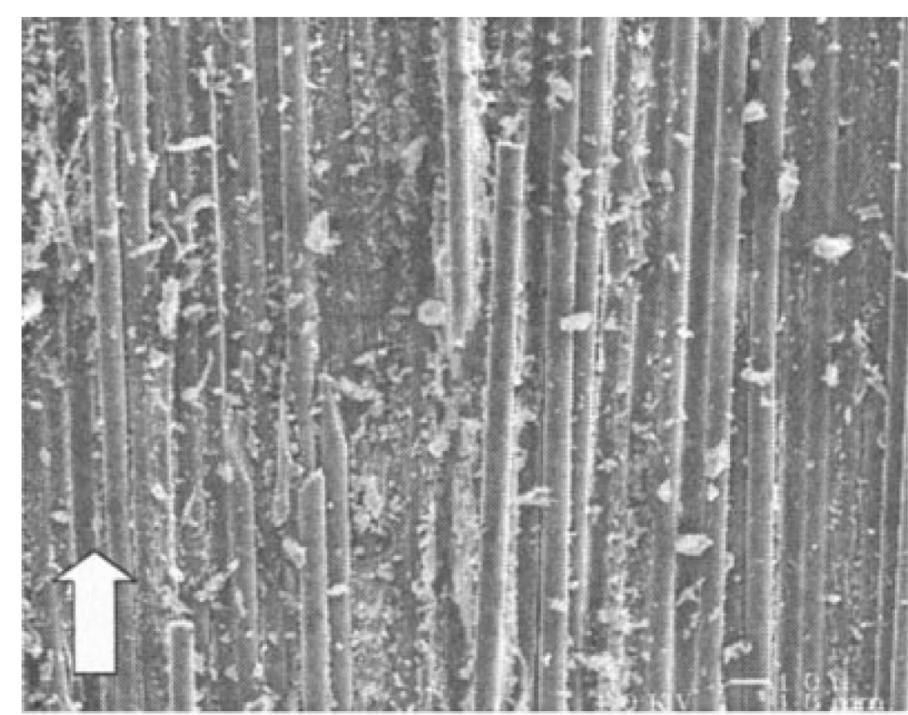

(a)

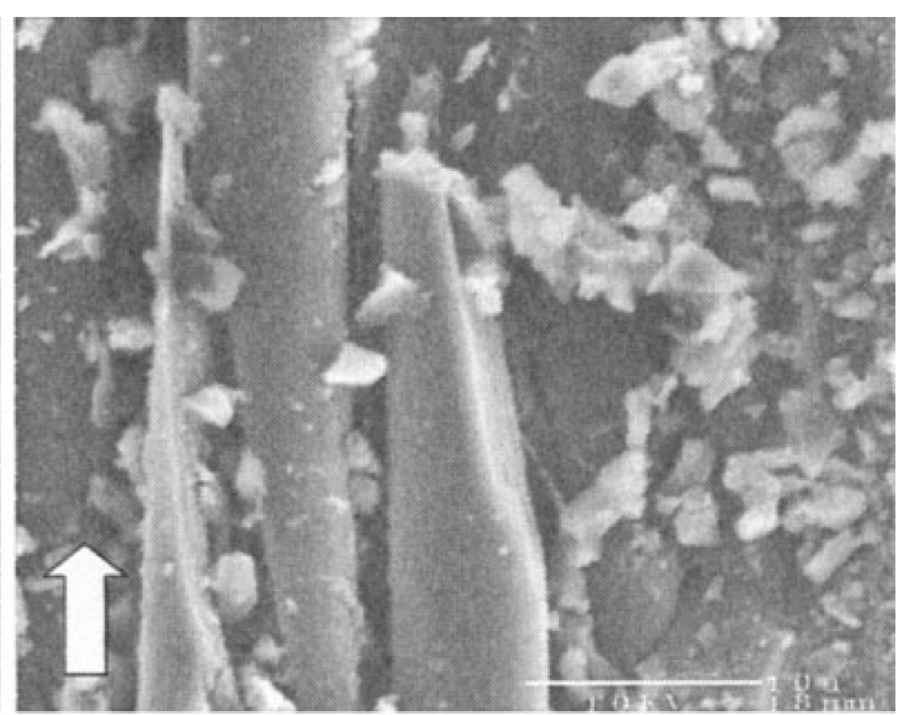

(b)

Figure 24. Fiber debonding and localized shearing failure (mode II case). Graphite fiber diameter: $\sim 7 \mu \mathrm{m}$.

\section{Conclusions}

Dynamic mode I and mode II interlaminar fracture toughness of an advanced composite laminate made of P7051S20Q-1000 prepregs has been determined using modified dynamic three-point bending and compact shearing test configurations based on the HPB and CDG setups. The transient loading history was recorded precisely by the HPB installed with a high-resolution digital oscilloscope, and the crack initiation and delay time were captured using the CDG. The critical DSIFs $\left(\mathrm{K}_{\mathrm{IDC}} / \mathrm{K}_{\mathrm{IIDC}}\right)$ have been determined by using a dynamic FEA code and a relation between DSIFs and transient CODs. Results show that under the present transient loadings, the $\mathrm{K}_{\mathrm{IDC}}$ value is about 80 $90 \%$ of the static one, while the $\mathrm{K}_{\mathrm{IIDC}}$ value is nearly unchanged. Dynamic failure mechanisms of the composite specimens were evaluated by SEM. For mode I loading, the failure microscopic mechanisms were dominated by matrix brittle fracture and fiber/matrix debonding, while for mode II loading, the failure microscopic mechanisms were controlled by fiber/matrix shear failure.

\section{Acknowledgments}

The authors would like to thank Professor Ruqiang Feng in the Department of Engineering Mechanics at the University of Nebraska-Lincoln for helpful suggestions and discussions, and graduates Mr. Yungui $\mathrm{Hu}$ and Mr. Hongfa Huang for kind help during the test setup. The materials for this study were provided by the Toray Composites America.

\section{References}

1. J. G. Williams, Fracture Mechanics of Polymers, Appl. Sci. Pub., London (1983).

2. W. J. Cantwell and J. Morton, ASME Appl. Mech. Rev., 22, 347 (1991).

3. S. Abrate, ASME Appl. Mech. Rev., 44, 155 (1991).

4. S. Abrate, ASME Appl. Mech. Rev., 47, 517 (1994).

5. R. L. Sierakowski, ASME Appl. Mech. Rev., 50, 741 (1997).

6. J. J. Carruthers, ASME Appl. Mech. Rev., 51, 635 (1998).

7. W. J. Cantwell and M. Blyton, ASME Appl. Mech. Rev., 52, 199 (1999).

8. I. M. Daniel, Exp. Mech., 39, 1 (1999).

9. M. S. Qatu, ASME Appl. Mech. Rev., 55, 325 (2002).

10. Y. A. Dzenis and J. Qian, Int. J. Solids Struct., 38, 1831 (2001).

11. A. A. Aliyu and I. M. Daniel, in Delamination and Debonding of Materials, W .S. Johnson, editor, ASTM STP876, American Society for Testing and Materials, Philadelphia, 336 (1985).

12. I. M. Daniel, I. Shareef, and A. A. Aliyu, in Toughened Composites, W. S. Johnson, editor, ASTM STP937, American Society for Testing and Materials, Philadelphia, 260 (1987).

13. I. M. Daniel, G. Yaniv, and J. W. Auser, Proc. 8th Int. Conf. Comp. Struct., I.H. Marshall, editor, Elsevier, New York, 258 (1987).

14. G. Yaniv and I. M. Daniel, Composite Materials Testing and Design 8th Conf., J.D. Whittcomb, editor, ASTM STP972, American Society for Testing and Materials, Philadelphia, 241 (1988).

15. A. J. Smiley and R. B. Pipes, J. Comp. Mats., 21, 671 (1987).

16. S. Mall, G. E. Law, and M. Katouzian, J. Comp. Mats., 21, 569 (1987). 
17. K. Friedrich, R. Walter, L. A. Carlsson, A. J. Smiley, and J. W. Gillespie, J. Mats. Sci., 24, 3386 (1989).

18. S. Hashemi, A. J. Kinloch, and J. G. Williams, J. Comp. Mats., 24, 918 (1990).

19. H. You and Y. J. Yum, J. Reinforced Plastic Comp., 16, 537 (1997).

20. W. J. Cantwell, J. Comp. Mats., 31, 1364 (1997).

21. L. Berger and W. J. Cantwell, Polym. Comp., 22, 271 (2001).

22. N. S. Choi, J. Mats. Sci., 36, 2257 (2001).

23. X. F. Wu and Y.A. Dzenis, Int. J. Fracture, 112, L9 (2001).

24. J. L. Tsai, C. Guo, and C. T. Sun, Comp. Sci. Tech., 61, 87 (2001).

25. M. S. Sohn and X. Z. Hu, Theoret. Appl. Fracture Mech., 25, 17 (1996).

26. J. Lambros and A. J. Rosakis, Exp. Mech., 37, 360 (1997).
27. C. Liu, A. J. Rosakis, R. W. Ellis, and M. G. Stout, Int. J. Fracture, 90, 355 (1998).

28. J. Lambros and A. J. Rosakis, Comp. Sci. Tech., 57, 55 (1997).

29. Y. P. Zhao, Adv. Mech. (in Chinese), 26, 362 (1996).

30. X.-F. Wu, "Fracture of Advanced Polymer Composites With Nanofiber Reinforced Interfaces," PhD Dissertation, University of Nebraska-Lincoln, Lincoln, Nebraska (2003).

31. J. R. Rice, ASME J. Appl. Mech., 35, 379 (1968).

32. L. D. Freund, Dynamic Fracture Mechanics, Cambridge University Press, New York (1998).

33. K. B. Broberg, Cracks and Fracture, Academic Press, New York (1999).

34. S. N. Alturi, Computational Methods in Mechanics of Fracture, Elsevier Science Publishers, New York (1986).

35. G. C. Sih, P. C. Paris, and G. R. Irwin, Int. J. Fracture Mech., 1, 189 (1965). 